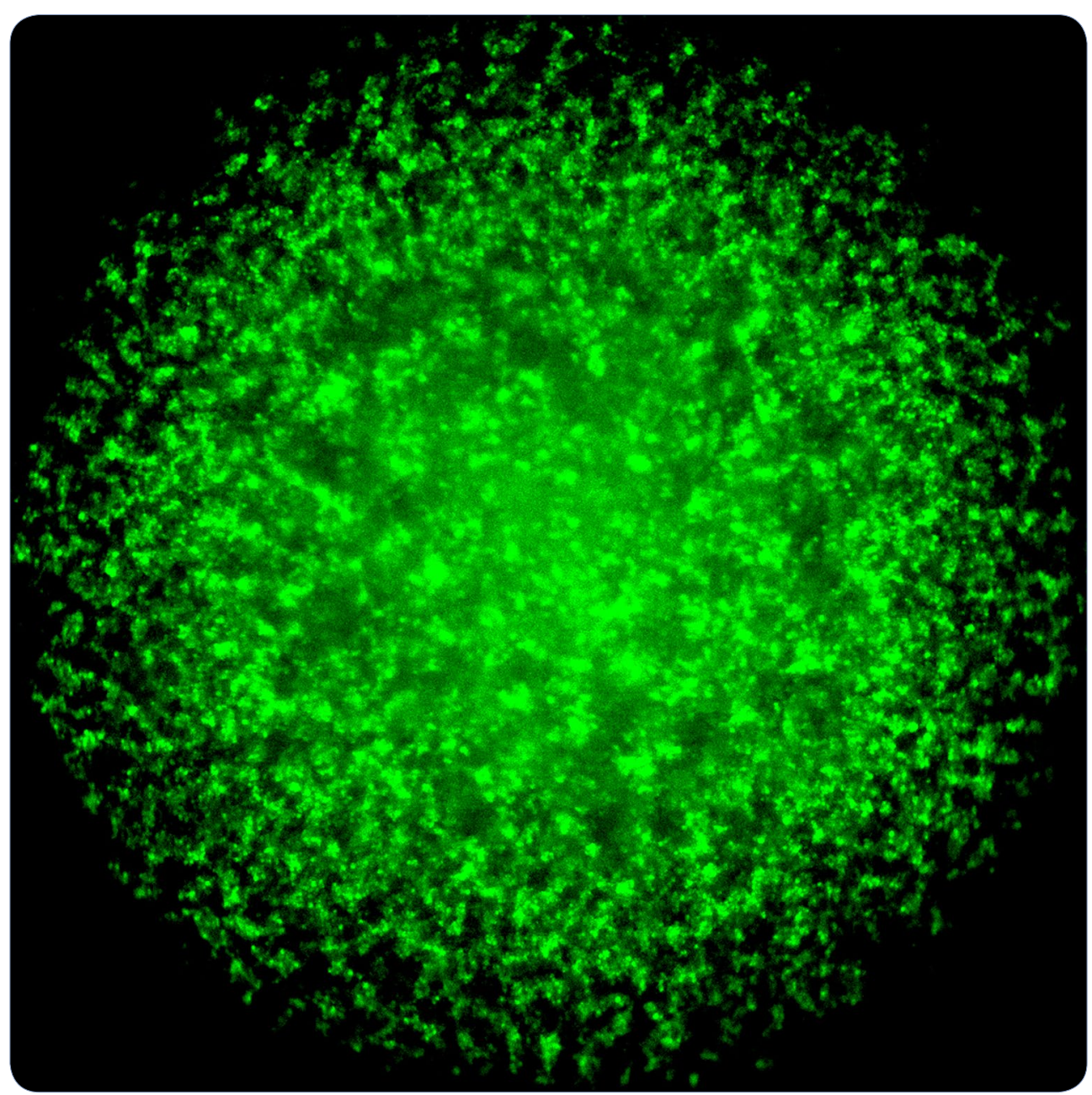

\title{
HIV-1 latency and virus production from unintegrated genomes following direct infection of resting CD4 T cells
}

Chan etal. 


\title{
HIV-1 latency and virus production
}

\section{from unintegrated genomes following direct infection of resting CD4 T cells}

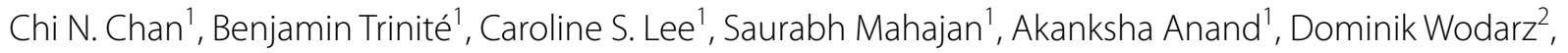
Steffanie Sabbaj ${ }^{3}$, Anju Bansal ${ }^{3}$, Paul A. Goepfert ${ }^{3}$ and David N. Levy ${ }^{1 *}$

\begin{abstract}
Background: HIV-1 integration is prone to a high rate of failure, resulting in the accumulation of unintegrated viral genomes (UDNA) in vivo and in vitro. UDNA can be transcriptionally active, and circularized uDNA genomes are biochemically stable in non-proliferating cells. Resting, non-proliferating CD4 T cells are prime targets of HIV-1 infection and latently infected resting CD4 T cells are the major barrier to HIV cure. Our prior studies demonstrated that uDNA generates infectious virions when T cell activation follows rather than precedes infection.

Results: Here, we characterize in primary resting CD4 T cells the dynamics of integrated and unintegrated virus expression, genome persistence and sensitivity to latency reversing agents. Unintegrated HIV-1 was abundant in directly infected resting CD4T cells. Maximal gene expression from uDNA was delayed compared with integrated HIV-1 and was less toxic, resulting in uDNA enrichment over time relative to integrated proviruses. Inhibiting integration with raltegravir shunted the generation of durable latency from integrated to unintegrated genomes. Latent uDNA was activated to de novo virus production by latency reversing agents that also activated latent integrated proviruses, including PKC activators, histone deacetylase inhibitors and P-TEFb agonists. However, uDNA responses displayed a wider dynamic range, indicating differential regulation of expression relative to integrated proviruses. Similar to what has recently been demonstrated for latent integrated proviruses, one or two applications of latency reversing agents failed to activate all latent unintegrated genomes. Unlike integrated proviruses, uDNA gene expression did not down modulate expression of HLA Class I on resting CD4 T cells. UDNA did, however, efficiently prime infected cells for killing by HIV-1-specific cytotoxic T cells.
\end{abstract}

Conclusions: These studies demonstrate that contributions by unintegrated genomes to HIV-1 gene expression, virus production, latency and immune responses are inherent properties of the direct infection of resting CD4T cells. Experimental models of HIV-1 latency employing directly infected resting CD4 T cells should calibrate the contribution of unintegrated HIV-1.

Keywords: HIV-1, Latency, Unintegrated DNA, Raltegravir, Integration, Cytotoxic T cells

\section{Background}

The failure of the majority of HIV-1 reverse transcripts to integrate into cellular chromosomal DNA has been apparent since the initial molecular descriptions of infection in vivo and in vitro $[1,2]$ (reviewed in $[3,4]$ ).

\footnotetext{
*Correspondence: dnlevy@nyu.edu

1 Department of Basic Science, New York University College of Dentistry, New York, NY 10010, USA

Full list of author information is available at the end of the article
}

Unintegrated HIV-1 DNA (uDNA) can be transcriptionally active, and production of early viral RNA and proteins has been observed in several cell types including resting CD4 $\mathrm{T}$ cells $[5,6]$. The number of transcriptionally active uDNA genomes can rival the number of active integrated proviruses [7]. Integration-defective lentiviral vector systems exploit this transcriptional activity, as well as biochemical stability of circularized extrachromosomal genomes in non-replicating cells [8-11] to 
achieve sustained ectopic gene expression in multiple lineages in vitro and in vivo (reviewed in [12]). uDNA gene expression is higher in non-proliferating cells compared with proliferating cells such as transformed cell lines and activated CD4 T cells, perhaps owing to a lack of dilution of uDNA templates and their RNA and protein products $[4,13]$.

We have previously reported that when cellular coinfection places an integrated provirus (iDNA) in a cell together with an unintegrated genome, viral complementation allows completion of the unintegrated virus' replication cycle without integration [14]. Recently, we reported that when HIV-1 infects resting $\mathrm{T}$ cells several days prior to $\mathrm{T}$ cell activation, uDNA alone generates infectious virions [6]. This stands in contrast to infection of activated $\mathrm{T}$ cells or cell lines, which support only transient and reduced levels of gene expression from uDNA without de novo virus production. Also in contrast to activated $\mathrm{T}$ cells and cell lines, gene expression from $\mathrm{uDNA}$ in resting $\mathrm{T}$ cells required delivery of virionassociated $\mathrm{Vpr}$, evidence of the uniqueness of uDNA gene regulation. The sequence of events which we found to induce production of infectious virions from uDNA mimics an in vivo situation where an infected resting $\mathrm{CD} 4 \mathrm{~T}$ cell is activated following migration to lymphoid tissues, which has been proposed as a mechanism facilitating the establishment of HIV-1 infection [15-17].

The predominant model for establishment of HIV-1 latency entails the infection of an activate CD4 $\mathrm{T}$ cell that returns to a resting state, thus removing support for viral transcription [18]. On the other hand, during acute and early infection, resting CD4 $\mathrm{T}$ cells are frequent targets of infection, constituting up to $90 \%$ of viral RNA+ cells in both HIV-1 infected humans and SIV infected macaques $[19,20]$. The latent reservoir is also rapidly established during acute infection [21-23], supporting the notion that direct infection of resting CD4 T cells may also contribute to the latent reservoir [19, 24, 25]. The majority of infected cells during untreated chronic infection also contain only unintegrated HIV-1 DNA [26]. Although unstimulated peripheral blood $\mathrm{T}$ cells are resistant to infection in vitro [27], in vivo, HIV-1 replicates in lymphoid (LT) and mucosal tissues that provide microenvironmental factors (cytokines, chemokines, DC and stromal cells) that support HIV-1 replication and maintain cell viability $[28,29]$. Several important in vitro models of HIV-1 latency utilize these factors to promote survival of resting CD4 $\mathrm{T}$ cells in vitro and to increase their permissiveness to infection by HIV-1 [30]. These systems are extensively utilized to test the response of latent HIV-1 to various compounds under scrutiny as latency reversing agents for curative therapies.
To this end, we recently described a convenient and relevant model system [6] in which resting peripheral blood CD4 $\mathrm{T}$ cells are treated with common gamma chain cytokines such as IL-4 that render them permissive to infection without inducing cell activation, though it is known that common gamma chain cytokines induce signaling pathways such as stat 5 or stat 6 and increase the expression of the survival protein Bcl-2 [31, 32]. IL-4, which we employ here, has been implicated in facilitating HIV-1 replication in lymphoid tissues [33] and, as a product of various immune cells including $\mathrm{T}$ cells [34], assists HIV transcription [35]. Recently we have shown that the primary function of primary gamma chain cytokines in assisting infection of resting CD4 T cells in vitro is to prevent HIV-1-induced cell death early after infection that is triggered by reverse transcription and virion $\mathrm{Vpr}$, rather than to enhance specific replicative processes [36]. With this system, we observed that latency persisted in resting CD4 $\mathrm{T}$ cells for several weeks, after which de novo virus production could be elicited by $\mathrm{T}$ cell activation. Importantly, using either the integrase inhibitor raltegravir or class I integrase mutants, we observed that durable, reversible latency was efficiently established by unintegrated HIV-1. Neither stimulation of cell activation nor virus expression induced proviral integration in this system. Virus production from uDNA was about one order of magnitude lower than from integrated proviruses but per-virion, was equally infectious [6].

In the present study we investigated the properties of uDNA and integrated proviruses (iDNA) in resting CD4 $\mathrm{T}$ cells, finding substantial and unexpected differences in the kinetics of their gene expression, persistence and virus production. We compared the responsiveness of latent unintegrated and latent integrated HIV-1 to a series latency reversing agents. Finally, we investigated the capacity of uDNA to down modulate Class I HLA expression and to prime infected cells for CTL killing. We conclude that unintegrated HIV-1 should be accounted for in models employing direct infection of non-proliferating cells such as resting CD4 T cells. Should these mechanisms pertain in vivo, the persistence of non-proliferating cells expressing HIV-1 proteins from uDNA may be threatened more by anti-HIV immunity than by biochemical degradation or viral cytopathic effects.

\section{Results}

Kinetics of gene expression by integrating and non-integrating HIV-1 in resting CD4 T cells

This study utilizes envelope-defective single round GFP reporter viruses expressing GFP in place of Nef, with Nef expressed at wild type levels downstream of an IRES element [37]. GFP fluorescence is generated during both 
the early and late gene expression phases, providing a sensitive measurement of overall HIV-1 gene expression that is highly correlated with virus production $[6,38]$. To examine the properties of unintegrated genomes, integration was inhibited either with raltegravir (RAL) or by mutation of HIV-1 integrase at the catalytic domain [39], which we have previously demonstrated are functionally equivalent $[6,14]$, inhibiting integration by at least $2-3$ orders of magnitude.

Given the long life span of resting CD4 $\mathrm{T}$ cells and the stability of circularized HIV-1 uDNA in them, we investigated the kinetics of gene expression from uDNA vs. iDNA in these cells after a single round of infection (Fig. 1). In the absence of further stimulation, integration-competent HIV-1 (No RAL) attained peak numbers of productively infected (GFP+) cells 7-9 days post infection (p.i.), consistent with studies demonstrating slowed kinetics of infection processes in resting vs. activated $\mathrm{T}$ cells $[27,40]$. Unintegrated HIV-1 (+RAL) displayed even slower expression kinetics, with expression remaining very low during the first 7-9 days, consistent with prior studies examining short term infections [41]. uDNA expression peaked around 2 weeks after infection, and parallel results were obtained using a class I integrase mutant (Additional file 1: Fig. S1A). At peak expression, nearly as many GFP+ cells were generated from unintegrated as from integration-competent HIV-1 (Fig. 1c), though uDNA GFP MFI was four fold lower (Additional file 1: Fig. S2A) and HIV-1 RNA levels were 6.3 fold lower (Additional file 1: Fig. S2B). No increase in the numbers of cells expressing GFP was observed after day 14-16, suggesting that by this time the majority of both integrated and unintegrated genomes which were destined to be spontaneously active had done so; therefore, this interval could be useful to study durable latency in the GFP-negative cells. In order to be particularly cautious regarding raltegravir efficacy [42], we added this integrase inhibitor 3 times over the course of the experiment, achieving a reduction from 0.48 integrated genomes per GFP + cell to less than or equal to 0.002 iDNA copies per GFP+ cell, i.e. less than one in $500 \mathrm{GFP}+$ cells contained an integrated provirus. (Additional file 1: Fig. $\mathrm{S} 2 \mathrm{C}$ ). In addition, the conformity of the raltegravir and integrase mutant results confirms that reversal of raltegravir activity is not playing a role. To test the effect of virus inoculum size on expression from uDNA, we reduced the virus inoculum eightfold, yielding a peak of $2 \%$ GFP + cells with the integration competent virus, or increased it twofold, observing little or no alteration in the kinetics of virus expression or the relative expression from the No RAL vs. +RAL infections (Additional file 1: Fig. S3A). Important for subsequent latency studies in GFP-negative cells, little HIV-1 RNA was expressed
(Additional file 1: Fig. S2B). As mentioned above, we recently reported that common gamma chain cytokines enhance in vitro infection of peripheral blood resting $\mathrm{T}$ cell primarily by allowing them to survive early reverse transcription- and Vpr-induced apoptosis rather than through enhancement of virus replication per se [36]. Here and in prior work [6] we found that GFP+ cells were almost exclusively found among the cells which did not proliferate. GFP+ cells showed identical cell cycle status as demonstrated by staining for pyronin Y/7AAD (not shown and [36]). CD69 is increased in GFP+ No RAL cells as we previously demonstrated, secondary to HIV-induced suppression of Foxo1 activity [43].

Next, we stimulated the entire cell population consisting of both GFP+ cells that are productively infected as well as the GFP-negative cells that comprise both uninfected and non-productively infected cells (Fig. 1a-c). $\alpha \mathrm{CD} 3 / \mathrm{CD} 28$ beads induce $\mathrm{T}$ cell activation, while the combination of a PKC activator prostratin (Pro) and a histone deacetylase inhibitor trichostatin A (TSA) more directly activates virus transcription. Integration-competent HIV-1 (Int-WT, No RAL) responded strongly to each stimulus beginning 1 day after infection (assayed on day 3). However, induction of maximal uDNA expression was only achieved with stimulation from day 7 (assayed on day 9) onward, demonstrating the uDNA requires more time than iDNA to establish responsiveness to these virus stimuli. There was a stimulation-induced increase in the GFP fluorescence of pre-existing GFP+ cells for both No RAL and +RAL cultures. However, stimulation increased the number of GFP+ cells only in the + RAL cultures, while the No RAL cultures remained at similar percentages of GFP+ cells. As we will describe in Fig. 5, there is rapid death of GFP+ cells only in No RAL cultures and this is accelerated by further stimulation. As a result, stimulation-induced cell loss masks latency reversal in No RAL cultures here, necessitating removal of pre-existing GFP + cells to specifically examine latency reversal, which is specifically explored in the following figures. Equivalent results were obtained using the Int-D116 N mutant (Additional file 1: Fig. S1A). Thus, not only does uDNA display slower expression kinetics, its availability for transactivation is delayed compared with integrating HIV-1 and indicates qualitative differences in gene regulation between iDNA and uDNA.

Importantly, two distinct peaks of GFP expression appeared in the No RAL cultures treated with Pro/ TSA days 5-7 (assay days 7-9, arrows in Fig. 1b). PCR analysis in our previous study indicated that the dimmer peak corresponds primarily to expression from unintegrated genomes, while cells in the brighter peak contain at least one integrated provirus [6]. Consistent with this, the bright population was lost upon raltegravir 


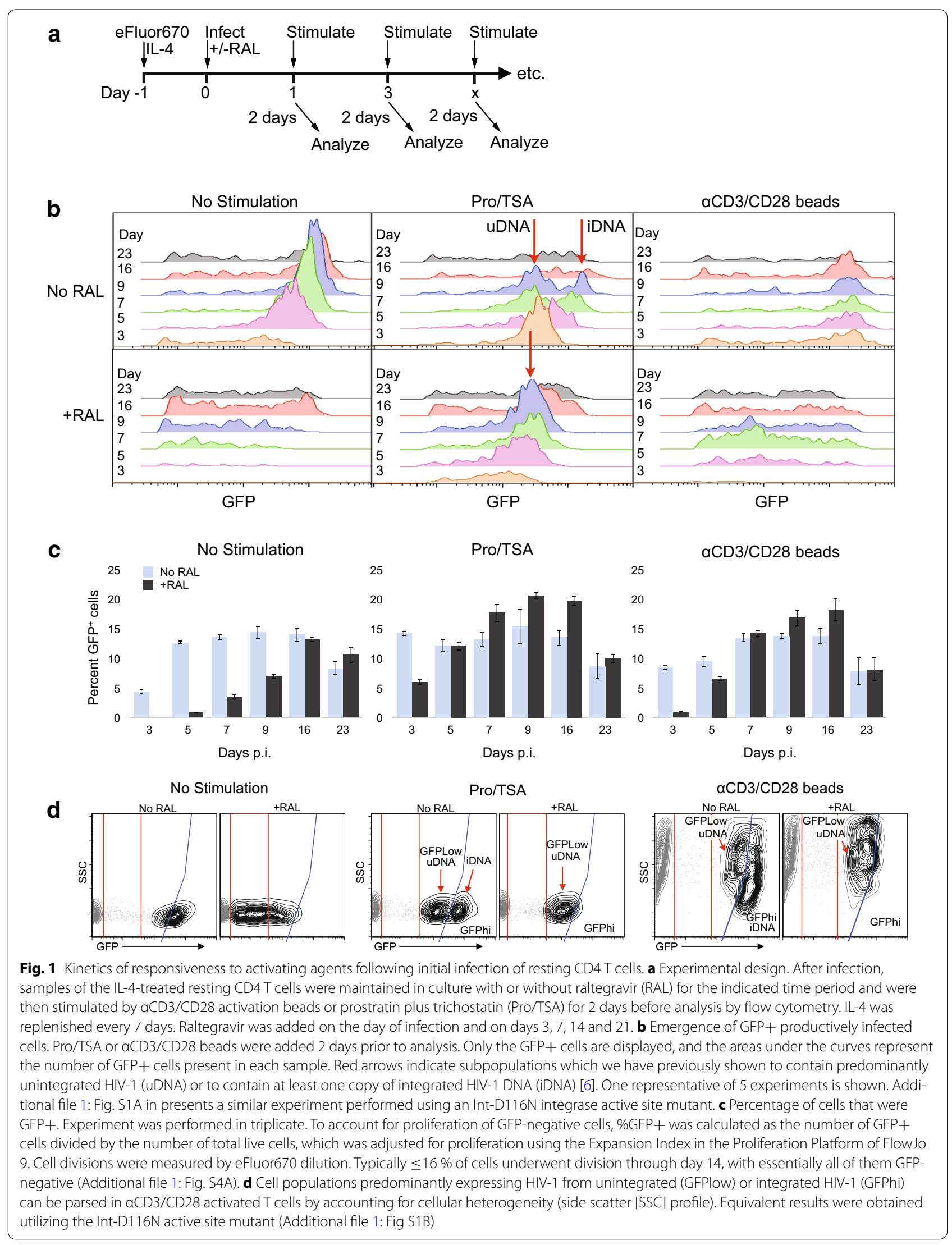


treatment (Fig. 1d) or Int-D116N mutation (Additional file 1: Fig S1B). Pro/TSA increased HIV-1 expression with little change in cell phenotype, including size and scatter profile (Fig. 1d). As a result, these cells remained largely homogeneous, and variations in GFP expression were easily discerned. By contrast, $\alpha \mathrm{CD} 3 / \mathrm{CD} 28$ beads generated a high degree of cell heterogeneity, which we hypothesized to have masked these subpopulations in the histograms of Fig. 1b. In fact, these two subpopulations were revealed in the activated $\mathrm{T}$ cells when the side scatter (which reports cell heterogeneity) and GFP expression were plotted together (Fig. 1d, Additional file 1: Fig S1B). Therefore, separate and distinct populations expressing HIV-1 from both integrated and unintegrated templates is a common phenomenon when resting CD4 T cells are stimulated several days after infection.

\section{Response of latent unintegrated vs. integrated HIV-1 to a series of latency reversing agents}

We next examined latent uDNA responses to several latency reversing agents (LRA) being considered as components of curative therapies. To this end, we established 14-day infections with the single round GFP reporter virus in the presence or absence of maximally effective raltegravir (Fig. 2a) and sorted eFluor670 ${ }^{\text {hi }}$ GFP-negative cells. Maintenance of the resting CD4 T state after sorting was evidenced by lack of expression of activation markers and G0-G1a cell cycle status in $>99.3 \%$ of eFluor670 ${ }^{\text {hi }}$ GFP-negative cells (Additional file 1: Figure S4). We then applied a panel of LRA or combinations of LRA, including PKC activators, HDAC inhibitors and P-TEFb agonists. We measured GFP fluorescence and virus release $24 \mathrm{~h}$ after stimulation (Fig. 2b). All LRA which were effective on integration-competent HIV-1 were also effective in reversing latency from uDNA. Prior studies, including our own, have found that unintegrated retroviral genomes are responsive to histone deacetylase inhibitors $[6,44-46]$, which we confirm.
Similar results were obtained in multiple experiments with either raltegravir (Additional file 1: Fig. S5) or with the Int-D116N virus (not shown). Infection without spinoculation resulted in a reduced infection frequency but the responses of latently infected cells to LRA were similar to spinoculated cells (not shown). Sorted eFluor$670^{\text {low }}$ GFP-negative cells, the proliferated population, did not generate GFP+ cells either spontaneously or following addition of latency reversing agents (not shown). This is interesting because homeostatic proliferation does not substantially alter the latent reservoir in vitro [47], thus neither productive infection nor latency in our system were efficiently established in cells which subsequently proliferated.

Strikingly, but also consistent with Fig. 1, at least as many and usually more GFP + cells were generated from the +RAL infections for each LRA than from the No RAL infections (Fig. 2b, c). This held true for infections at lower and higher MOI (Additional file 1: Fig. S3B) and for Int-D116 $\mathrm{N}$ viruses (not shown). An expanded panel of LRA produced similar results (Additional file 1: Fig. S5, and Expt. 2 in Fig. 3c, d, g, f). Fewer virions were generated from the + RAL cells in each culture (Fig. 2d), and fewer virions were released per GFP+ cell (Fig. 2h) that was consistent with the lower transcription from unintegrated genomes. Virus production was highly correlated with GFP fluorescence intensity similarly for the No RAL and +RAL infections (Fig. 2f). However, the dynamic range of the induction of both GFP + cells and the GFP fluorescence intensities were greater for the +RAL infections (bracketing lines in Fig. 2e, f). This translated into the finding of Fig. 2g, where, as the strength of the activators increased (more virions were released), the $+\mathrm{RAL}$ virus production approached closer to the No RAL virus production (Fig. 2g). This increase in the relative output from the +RAL infections was the result of both more GFP+ cells being generated as well as an increase in the output per cell relative to the No RAL cells (Fig. 2h),

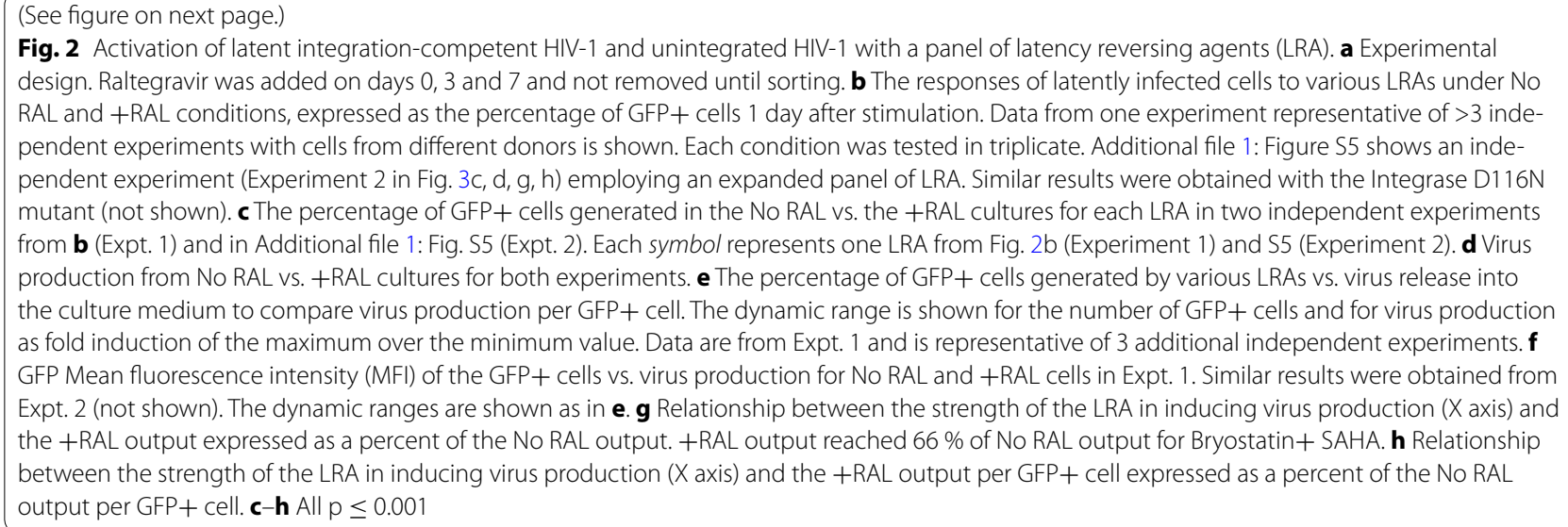




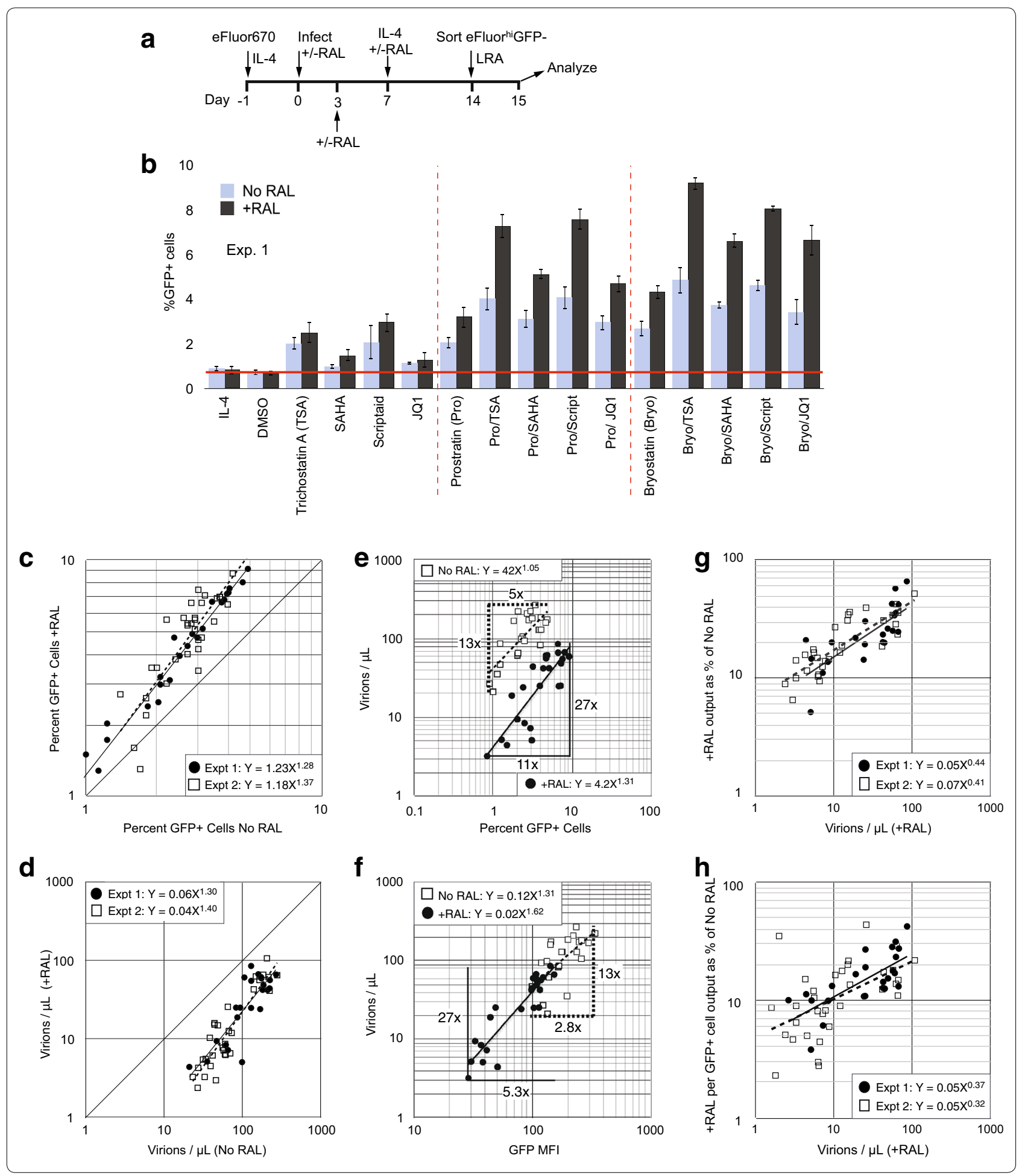


consistent with the greater dynamic range seen in the GFP fluorescence (Fig. 2f). These results further indicate that uDNA latency and transactivation are regulated differently from integrated proviruses.

With regard to individual LRA and classes of LRA, the PKC agonists (prostratin, bryostatin) were overall the most effective, activating viruses within the most cells and inducing the most virus production from both integrating and unintegrated HIV-1 (Fig. 2b, Additional file 1: Fig S5). Histone deacetylase inhibitors [TSA, SAHA (vorinostat), Scriptaid] and the P-TEFb agonists JQ1 and HMBA only weakly activated latent integrated or unintegrated viruses on their own, but they enhanced virus activation in combination with PKC activators, consistent with the possible enhancement of stochastic fluctuations in transcription [48]. Disulfiram was ineffective in our system on either integrating or unintegrated HIV-1, consistent with other recent reports $[49,50]$. Interestingly, synergy between agents was obtained only with PKC activators plus HDACi or JQ1 and only in the raltegravir cultures (Table 1). This provides further evidence that uDNA and iDNA are differentially regulated at the transcriptional level.

A recent study indicated that HIV-1 constructs rendered incapable of replicating by mutations or deletions of the env gene can revert to wild type through recombination with envelope expression plasmids following cotransfection of producer cells [51]. To test if replication competent viruses might be contributing to our results, we treated infected resting CD4 $\mathrm{T}$ cells with the protease inhibitor indinavir on the day of infection and on day 5 post infection with the non-nucleoside reverse transcriptase inhibitor efavirenz in order to block the spread of any reverted viruses. There was no effect on the generation of latently infected cells, indicating that reversion was not contributing to results (not shown).

\section{Kinetics of latency reversal}

Twenty-four hours after stimulation of latently infected cells is a convenient and frequently utilized time at which to analyze latency reversal [30]. However, our data indicating differential regulation of uDNA and iDNA prompted us to test if uDNA also presents differential kinetics of latency reversal. To this end, we performed a latency experiment with cells from 3 donors, sorting eFluorhiGFP- cells 14 days after infection then stimulating them with Pro/TSA. We analyzed the emergence of GFP expression and virus production over the following 3 days (Fig. 3). During the initial $14 \mathrm{~h}$ the No RAL cells generated from 3.7 to 7.9 fold more virus than the + RAL cells (Fig. 3b, c). However, after this initial burst of production, the relative differences in virus output decreased (Fig. 3c). With Donor 3 cells, which had the highest initial infection frequency, the + RAL virus production even exceeded the No RAL production by 2 days after stimulation. We then calculated virus output per $\mathrm{GFP}+$ cell, accounting for the differences in the number of GFP+ cells and changes in their numbers over time (Fig. 3d). On a per-cell basis the rate of virus production from the No RAL cells decreased relative to the + RAL cells. For Donor 3 cells, the output per GFP + cell equaled the No RAL cells after 2 days. Thus, uDNA latency reversal initially displayed slower kinetics compared with integrated proviruses, but the differences in virus production between the No RAL and +RAL declined over time, indicating a more sustainable virus release from $\mathrm{uDNA}$.

\section{Distribution of integrated and unintegrated genomes in productive infection and latency}

We next analyzed the content of cells for integrated and unintegrated HIV-1 before and after latency reversal. Fourteen days after direct infection of resting CD4 $\mathrm{T}$ cells, we sorted cells into 4 groups based on GFP fluorescence intensity (Fig. 4a). Using qPCR we then directly measured total HIV-1 genomes, integrated proviruses and 2-LTR circles (Fig. 4b). The primers to measure total DNA amplify all integrated and unintegrated species of HIV-1 DNA. 2-LTR circles have been observed to be formed as a minor fraction of the unintegrated species, forming about $1 / 30$ th of the total uDNA, with 1-LTR circles and linear uDNA constituting the remainder [52, 53]. The overall amount of uDNA is calculated as total DNA minus integrated DNA.

The most obvious result, consistent with prior studies $[54,55]$, was that uDNA was formed in excess of integrated proviruses. In this infection of resting $\mathrm{T}$ cells, uDNA was present on day 14 p.i. at nearly tenfold excess over iDNA (Additional file 1: Table S1) amongst all cells (GFP+ and GFP-neg.). Cells with the highest GFP fluorescence $(+++$ cells corresponding to the prominent peak in Fig. 1b) contain at least one integrated genome consistent with prior results $[6,14]$. By contrast, single + and double ++ cells contained less than one iDNA per cell ( 0.2 and 0.3 in the + and ++ cells, respectively), thus between 67 and $80 \%$ of these dimmer cells expressed GFP from uDNA only. In 5 similar experiments utilizing 5 different cell donors, a substantial fraction of GFP+ cells $(9-62 \%)$ contained only uDNA (Additional file 1: Table S2).

To examine the contribution of unintegrated DNA to latency we treated sorted GFP-negative cells with Pro/ TSA (Fig. 4c), then performed a second sort and analyzed the DNA content of GFP-neg. and GFP+ cells (Fig. 4d). Similar to the initial infection, uDNA predominated in the GFP dim cells while there was at least one integrated provirus in the GFP bright cells. Interestingly, uDNA was 


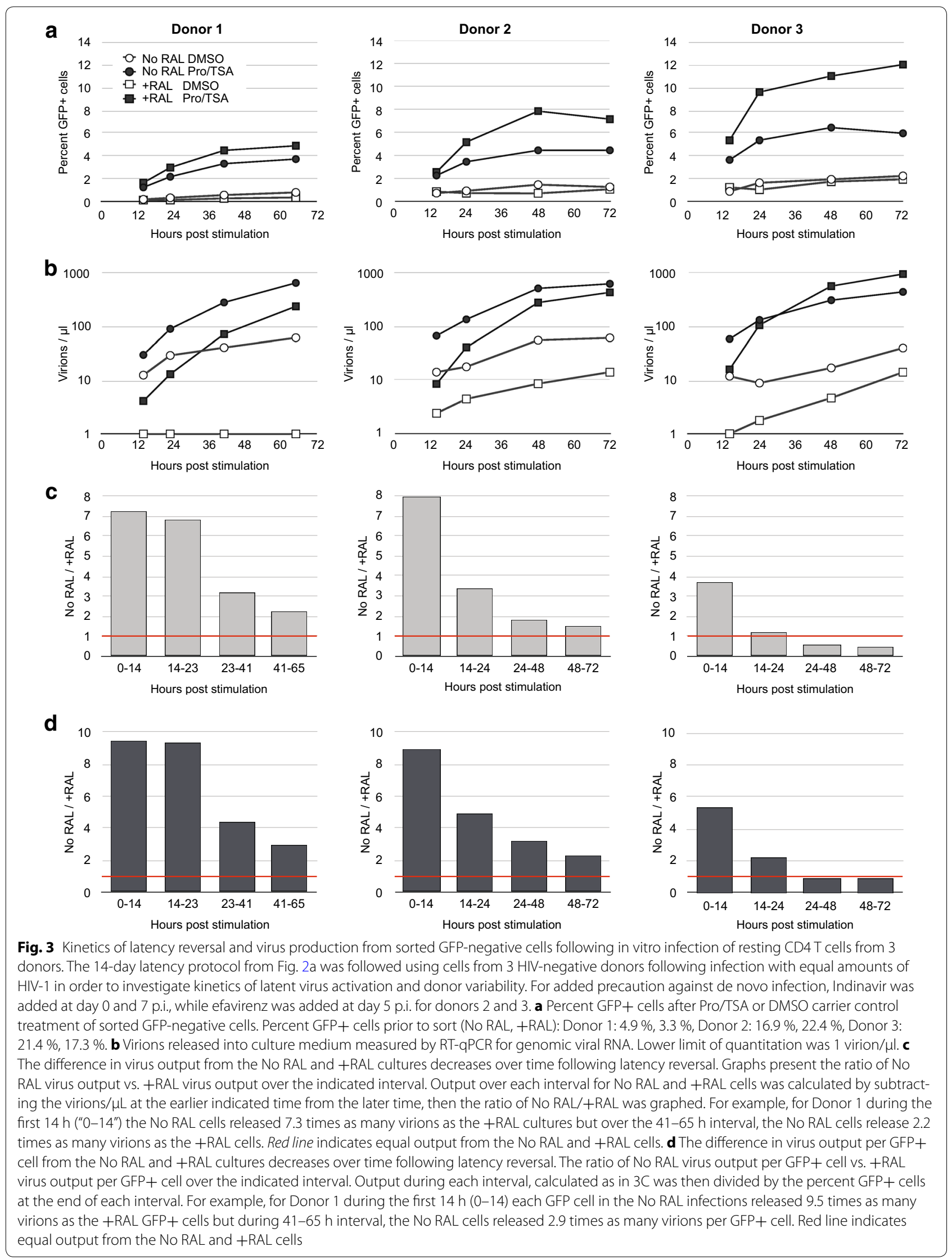


Table 1 Synergy indices for combinations of latency reversing agents

\begin{tabular}{|c|c|c|}
\hline & No RAL & $+\mathrm{RAL}$ \\
\hline \multicolumn{3}{|l|}{ Bryostatin } \\
\hline$+\mathrm{TSA}$ & $1.06 \pm 0.13$ & $1.49 \pm 0.28$ \\
\hline$+\mathrm{SAHA}$ & $0.94 \pm 0.07$ & $1.09 \pm 0.05$ \\
\hline +Scriptaid & $0.95 \pm 0.05$ & $1.19 \pm 0.09$ \\
\hline$+\mathrm{JQ1}$ & $0.85 \pm 0.06$ & $1.14 \pm 0.10$ \\
\hline$+\mathrm{HMBA}$ & $0.92 \pm 0.13$ & $1.12 \pm 0.16$ \\
\hline +Disulfiram & $0.83 \pm 0.06$ & $0.79 \pm 0.03$ \\
\hline \multicolumn{3}{|l|}{ Prostratin } \\
\hline$+\mathrm{TSA}$ & $1.02 \pm 0.04$ & $1.44 \pm 0.14$ \\
\hline$+\mathrm{SAHA}$ & $0.96 \pm 0.08$ & $1.30 \pm 0.19$ \\
\hline +Scriptaid & $0.97 \pm 0.05$ & $1.42 \pm 0.18$ \\
\hline$+\mathrm{JQ1}$ & $0.87 \pm 0.07$ & $1.19 \pm 0.16$ \\
\hline$+\mathrm{HMBA}$ & $0.63 \pm 0.10$ & $0.77 \pm 0.29$ \\
\hline +Disulfiram & $0.55 \pm 0.14$ & $0.68 \pm 0.14$ \\
\hline \multicolumn{3}{|l|}{ JQ1 } \\
\hline$+\mathrm{TSA}$ & $0.72 \pm 0.08$ & $0.88 \pm 0.22$ \\
\hline$+\mathrm{SAHA}$ & $0.87 \pm 0.11$ & $0.90 \pm 0.11$ \\
\hline +Scriptaid & $0.84 \pm 0.15$ & $0.90 \pm 0.10$ \\
\hline \multicolumn{3}{|l|}{ HMBA } \\
\hline+ TSA & $0.63 \pm 0.17$ & $0.78 \pm 0.03$ \\
\hline$+\mathrm{SAHA}$ & $0.62 \pm 0.21$ & $0.81 \pm 0.11$ \\
\hline +Scriptaid & $0.69 \pm 0.14$ & $0.91 \pm 0.14$ \\
\hline \multicolumn{3}{|l|}{ Disulfiram } \\
\hline$+\mathrm{TSA}$ & $0.68 \pm 0.11$ & $0.72 \pm 0.13$ \\
\hline+ SAHA & $0.63 \pm 0.06$ & $0.69 \pm 0.06$ \\
\hline +Scriptaid & $0.85 \pm 0.17$ & $0.98 \pm 0.19$ \\
\hline
\end{tabular}

Synergy indices were calculated from 3 independent experiments with different cell donors, based on the number of GFP + cells. Synergy was calculated according to [95] and synergy indices significantly $>1$ are indicated in italicized text. Additional file 1: Figure S5 contributes data for one of the 3 experiments

still the majority population in the bright cells. A prior study in proliferating cells has shown that unintegrated genomes can constitute a similar proportion of transcriptionally active genomes as integrated proviruses [7], however ours is the first study conducted in resting CD4 T cells and to directly parse cell subpopulations and analyze DNA content. There were 20 times more uDNA than iDNA genomes in the GFP-negative cells from the first sort, but only 5.5 times as many in the newly activated GFP + cells from the second sort (Additional file 1: Table S1) indicating that silent iDNA genomes were more likely to be activated by the Pro/TSA treatment than were silent uDNA genomes, a result consistent with the differential latency regulation. There could also be a higher proportion of defective or otherwise unresponsive uDNA than iDNA genomes. Importantly, no increase in integration resulted from this stimulation 15 days after infection (Fig. 4b vs. d, Additional file 1: Table S1), consistent with the short (1 day) half-life of pre-integration complexes [56].

Consistent with Fig. 1, raltegravir increased the generation of GFP + cells from the latent pool (3.2 vs. $1.88 \%$ ) while inhibiting integration by $\geq 280$ fold (Fig. $4 \mathrm{e}-\mathrm{h}$ ). Raltegravir also increased the appearance of 2-LTR circles by several fold (Fig. 4f), as expected [6, 57, 58]. As in the No RAL cultures, no increase in integration resulted from this stimulation 14 days after infection, in agreement with our prior study utilizing both raltegravir and integrase active site mutants [6], but in contrast to a recent study in which removal of raltegravir 2-3 days after infection allowed integration to proceed [42]. The difference in results from that study to ours is likely to be the considerable differences in the timing between infection and the removal of raltegravir. In the current study we left raltegravir in the culture for the duration of the 14 days prior to sorting and added it 2 additional times on days 3 and 7 . The measured quantity of residual integration events in Fig. $4 \mathrm{f}$ and h, likely caused by an integrase-independent mechanism, cannot account for the expression of HIV-1 in the raltegravirtreated cultures.

\section{Persistence of cells expressing HIV-1 from unintegrated genomes}

The lower but more sustained gene expression and de novo virus production from uDNA vs. iDNA suggested the possibility that these are less cytopathic to cells when uDNA is the template. Lower cytopathicity could enhance uDNA persistence and allow more prolonged virus release from the uDNA template. To test this, at day 7 post infection we sorted GFP+ cells infected with an integrase WT HIV-1 or an Integrase active site mutant (Integrase D116N), then analyzed cell survival of the sorted GFP+ cells and virus production from them in the absence of further stimulation (Fig. 5a). As we predicted, the GFP + cells productively infected with the integrase mutant died at a considerably lower rate than cells productively infected with the integrase WT virus, and they generated $27 \%$ of the total de novo virus output from the Integrase WT virus over this time. After about 12 days in these cells the death curve of the Int-WT virus inflected to be approximately parallel with the Int-D116N virus, suggesting that cells expressing GFP from integrated viruses may have become depleted from the Int-WT infected cells, with relative enrichment of cells expressing GFP from uDNA (shown to arise in Fig. 4) in this nonreplicating cell population.

To test this hypothesis, we sampled productively infected cells at 3 intervals after infection and analyzed their DNA content (Fig. 5b-d). Here we employed a reporter virus expressing the cell surface molecule 


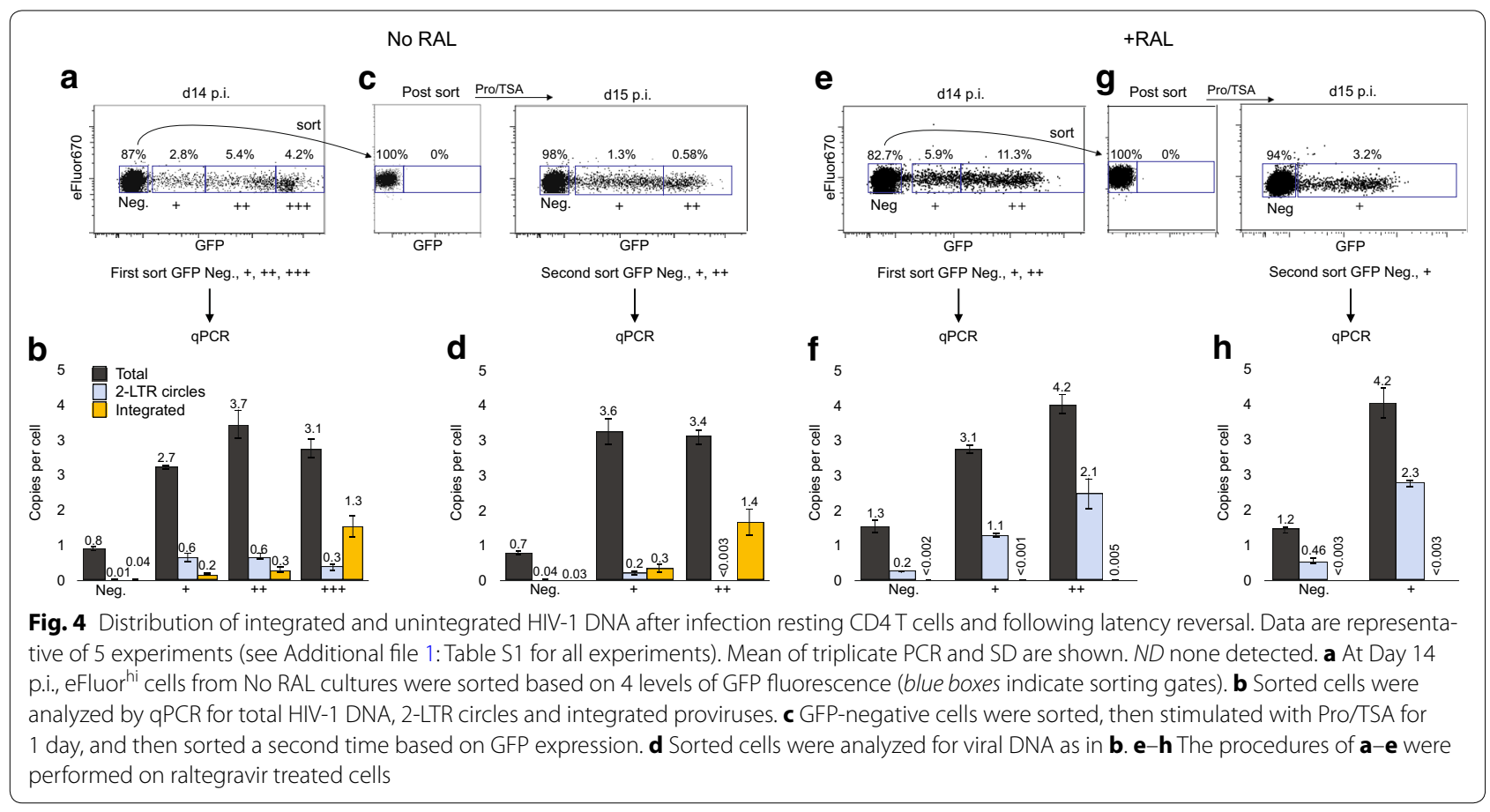

Heat Stable Antigen (HSA, a.k.a. murine CD24) in place of GFP [43] which allows purification of productively infected (HSA+) cells with anti-HSA magnetic beads. Between days 5 and day 7 there was no loss of either integrated or unintegrated HIV-1 DNA in these cells infected without raltegravir added (Fig. 5c, d). However, between days 7 and 14 there was a ninefold reduction in the integrated proviruses among the HSA+ cells but only a 2.6 fold reduction in total DNA at day 7 p.i., consistent with our hypothesis that the cells expressing virus solely from the uDNA template have a survival advantage over cells expressing virus from an integrated template. Confirming our model, HSA+ cells collected on day 7 from the No RAL condition died at a greater rate than either the HSA - cells or HSA+ cells from raltegravir treated culture (Fig. 5e). Cells expressing HIV-1 from uDNA (+RAL, HSA+ cells) died at a similar rate to the HSAnegative cells, confirming that uDNA gene expression is not particularly toxic. All of the cells from day 14 died at an equal rate, which is consistent with the observed depletion of cells expressing HIV from iDNA by this point. In separate experiments, $\alpha \mathrm{CD} 3 / \mathrm{CD} 28$ beads accelerated death of purified No RAL HSA+ (or GFP+) cells but not +RAL HSA+ (or GFP+) cells (Additional file 1: Fig. S6). Thus, owing to its reduced toxicity, genetically active uDNA can have a persistence advantage in resting, non-proliferating $\mathrm{T}$ cells compared with active integrated proviruses.

\section{One or two rounds of stimulation do not activate all unintegrated latent genomes}

The efficacy of any shock and kill regimen will require that essentially all replication competent HIV-1 genomes be activated. Prior studies, however, have demonstrated failure of single or repeated strong stimuli to accomplish this in ex vivo and in vitro systems $[59,60]$. Here, we investigated whether a single round of strong stimulation can activate all unintegrated latent genomes (Fig. 6). Fourteen days after infection, we

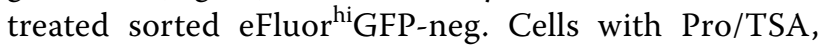
or activated them with $\alpha \mathrm{CD} 3 / \mathrm{CD} 28$ beads plus IL-2, or left them untreated (First Stimulation) (Fig. 6b, c). The $\alpha \mathrm{CD} 3 / \mathrm{CD} 28$ beads induced cell enlargement and proliferation in $\geq 99 \%$ of the cells, indicating essentially complete activation. Pro/TSA, which does not induce T cell activation, resulted in no cell enlargement or proliferation but similar HIV-1 induction. We counted the total number of GFP+ cells generated from the GFP-negative sorted cells, and calculated the percent GFP+ cells based on the number of cells placed in each well before the first stimulation (Fig. 6c). Three days later we sorted GFP-neg. cells a second time from each culture and (re) stimulated them with one of the agents or with nothing (Second Stimulation). This yielded 9 combinations of first and second stimuli (Fig. 6d). We calculated the percent GFP+ cells based on the number of cells placed in each well before the second stimulation (Fig. 6e). Stimulation in the first round reduced the number of GFP+ 

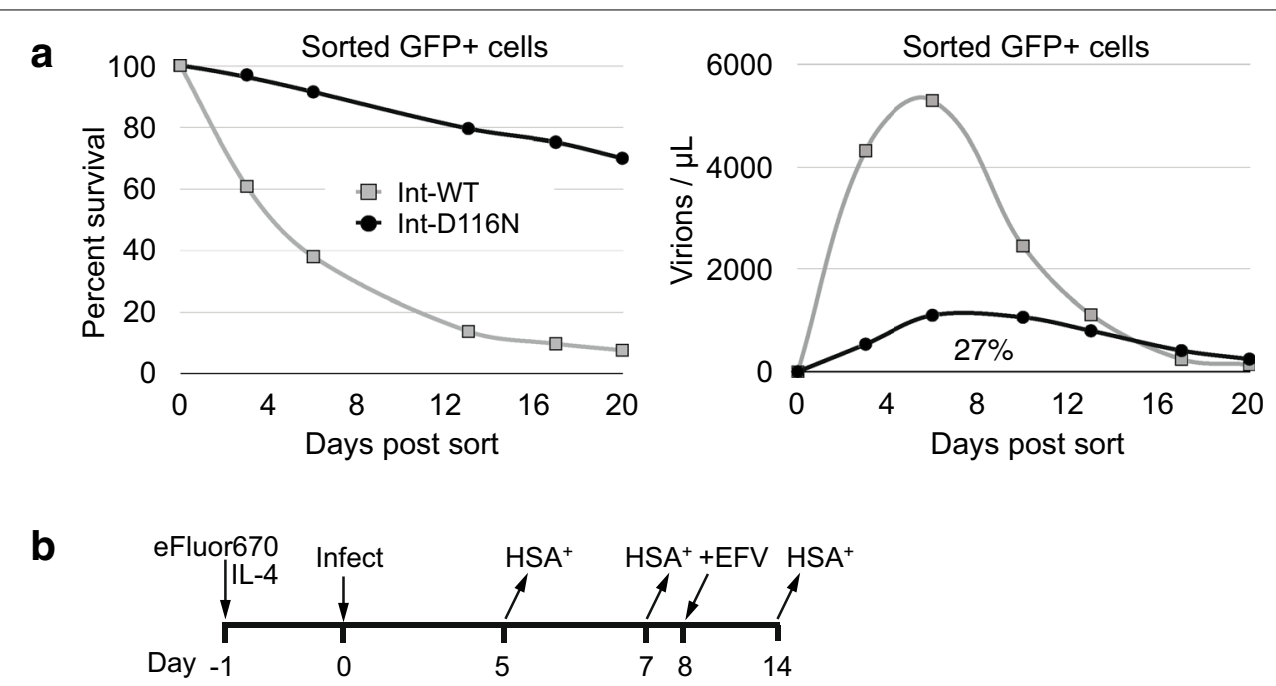

C

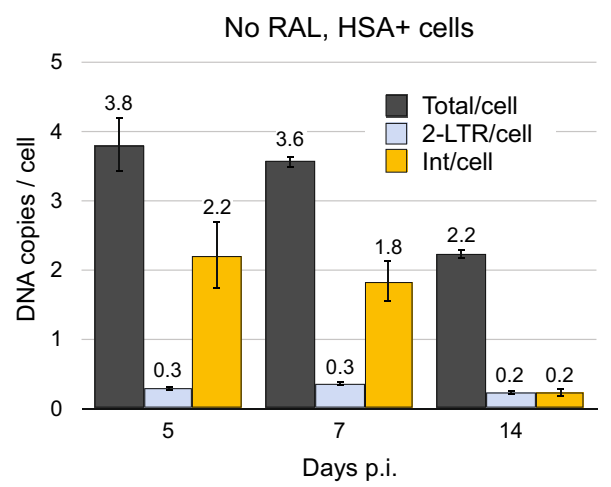

e

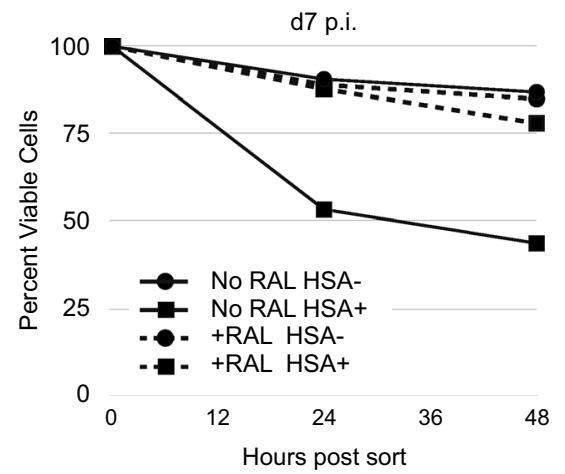

d
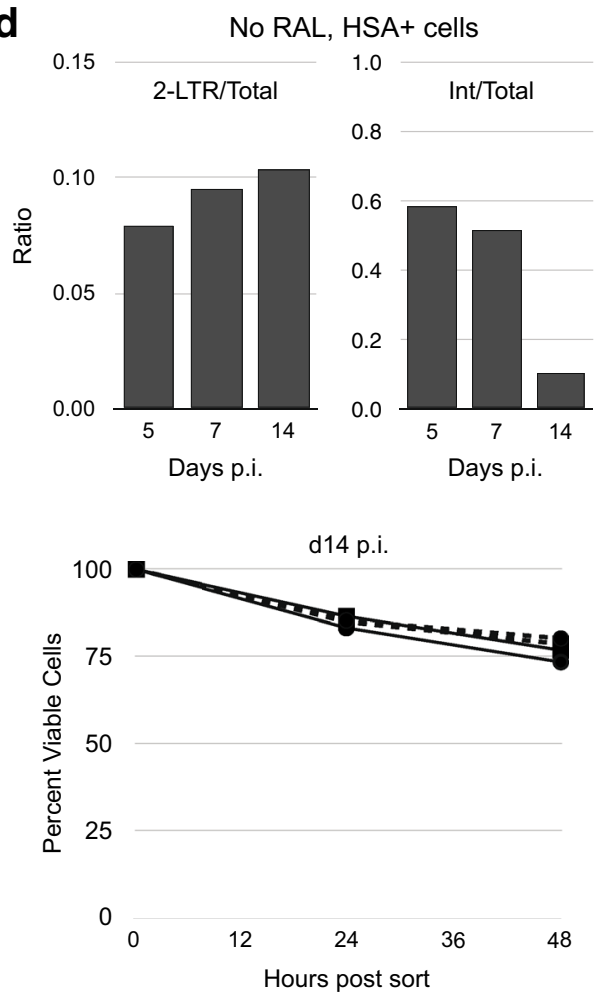

Fig. 5 Preferential loss of resting CD4 T cells infected with integrated proviruses. a Productively infected GFP+ cells containing Int-WT or Int-D116N HIV-1 were sorted by FACS 7 days after infection and placed back into culture. Survival of the GFP+ cells was assessed by flow cytometry on the indicated days, and virus production from the FACS purified GFP+ cells was measured by RT-qPCR for viral RNA present in the culture medium as described [6]. In this experiment an Envelope+ virus was employed. b Experimental design for c-e. Resting CD4T cells infected with HSA-reporter viruses were maintained in IL-4 \pm RAL for 14 days. At the indicated time points $\mathrm{HSA}^{+}$cells in each sample were isolated using anti-HSA antibody coupled to magnetic beads. Efavirenz was added to all cells on day 8. HSA Positive and negative cells were separated using the MACS system. Cell survival was measured by forward and side scatter analysis. Data present one of two independent experiments. c Productively infected HSA ${ }^{+}$cells purified from No RAL cultures at day 5, 7 and 14 p.i. were analyzed for viral DNA. d The ratios of 2-LTR/total HIV-1 DNA in comparison with the ratio of integrated/total HIV-1 DNA for No RAL purified HSA+ productively infected cells. e HSA ${ }^{+}$and HSA-neg. cells were purified at day 7 and 14 p.i. and placed into fresh medium. Cell viability of these individual populations was monitored by flow cytometry over $48 \mathrm{~h}$ 
cells generated in the second round. However, a second stimulation nevertheless generated measurable numbers of GFP + cells. These finding held true in both the raltegravir treated and untreated cultures. In fact, more GFP + cells were generated in the raltegravir cultures in the first and second round stimulations, with the exception of cells that were activated by $\alpha \mathrm{CD} 3 / \mathrm{CD} 28$ beads in the first round. We previously demonstrated [6] that cell proliferation antagonizes uDNA gene expression, so it seems likely that that this effect plus the partitioning of uDNA genomes as the cells divided reduced the number of uDNA genomes that could be activated in $\alpha \mathrm{CD} 3 /$ CD28 activated cells.

In a variant of this experiment, we stimulated cells infected with the single round virus twice (day 8 and day 11 post infection) prior to sorting for GFP-negative cells. Similar to Fig. 6, we observed latent viruses emerge 2 days later with or without further stimulation, further confirming a strong stochastic component to latency reversal (Additional file 1: Fig. S7). Overall, these results indicate that both uDNA latency and integrated proviral latency can resist a single or even double exposure to stimuli intended to reverse the latent state.

\section{Failure to down modulate HLA Class I expression and CTL responses to HIV-1 epitopes expressed from integration competent and defective HIV-1}

Observations of gene expression from uDNA prompted the notion that this could expand the antigenic repertoire of HIV-1 and the number of cells vulnerable to CTL recognition [61]. We first measured the ability of uDNA to down modulate receptors required for immune recognition. In our system, integration-competent HIV-1 efficiently down modulated CD4 (Fig. 7a) and HLA Class I (Fig. 7b) in the majority of either resting CD4 T cells or cells subsequently activated according to the post-infection activation (Post-activation) procedures utilized in this work and in our prior study [6] which demonstrated that high level uDNA expression is only achieved by this sequence of events and not by infection of pre-activated $\mathrm{T}$ cells. Post-activation of the cells resulted in the death of more GFP+ cells than GFP-neg. cells, resulting in a decrease in the percent GFP + . HLA Class I down modulation by the integrating virus was biphasic and observed only in cells with GFP expression higher than achieved by uDNA. HIV-1 Nef-dependent HLA Class I down modulation (reviewed in [62]) has been shown to inhibit CTL recognition [63]. Similar to previous reports [64] uDNA was able to down modulate CD4, though not as efficiently as integrating virus. On the other hand, HLA Class I was barely affected by uDNA gene expression, suggesting continued high vulnerability to CTL recognition might result.

Next, we examined the ability of HIV-1-specific CTL to recognize and eliminate cells expressing HIV-1 proteins from unintegrated templates (Fig. 7c). CD8 cytotoxic T cell lines specific for HIV-1 Nef and Gag were developed from HIV-1 infected individuals as previously described $[65,66]$. These CTL lines were co-cultured with HIV1-infected HLA Class I-matched target cells at varying CTL to target cell ratios. Negative controls included HLA Class I mismatched infected target cells. Killing of HIV-1 expressing cells was measured as a reduction in the percentage of GFP + cells by flow cytometry, and non-specific killing of the HLA Class I mismatched cells was subtracted from these data. Both Gag-specific and Nef-specific CTL recognized and eliminated GFP+ cells expressing HIV-1 proteins from HIV-1 with wild-type integrase or from uDNA (Int-D116N) with the efficiency of killing titrating according to the CTL:target ratio. Perhaps not-surprisingly, given the weaker expression of Gag vs. Nef from uDNA [6], CTL against Gag more efficiently killed Int-WT infected cells than Int-D116N infected cells. This would be consistent with a recent study indicating that 2-LTR uDNA is cleared less efficiently by CTL than integrated proviruses [67]. On the other hand, Nef CTL more efficiently killed cells infected with the integrase deficient virus, so uDNA clearance could be epitope-specific. It is tempting to speculate that failure to down modulate HLA Class I could allow greater vulnerability to CTL killing of cells expressing early vs. late gene products from unintegrated HIV-1.

(See figure on next page.)

Fig. 6 A single round of maximum T cell activation does not induce the expression of all latent unintegrated or integrated viruses. a Experimental

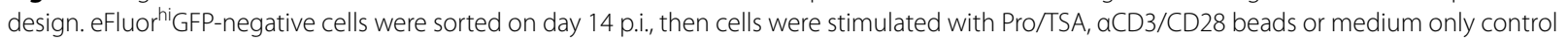
$(\varnothing)$. Three days later (day 17) all GFP-negative cells were purified in a second sort and 30,000 cells per well were (re)stimulated in triplicate. Efavirenz was added on days 14 and 17 to sorted cells as an added precaution against virus spread. b Flow cytometric analysis of cells at the end of the first three day treatment. GFP+ cells (light grey dots) are overlaid on GFP-negative cells (black dots). Undivided cells lie above the red lines. c The percentage of GFP+ cells generated after the first round of stimulation calculated based on the total number of GFP+ of the cells placed in the wells on day 14. d Flow analysis of cells after the restimulation. Cells that remained GFP-negative after the first round of stimulation were sorted and equal numbers of these cells were re-stimulated with Pro/TSA, aCD3/CD28beads or medium alone $(\varnothing)$. e The percentage of GFP+ cells generated after the second round of stimulation calculated based on the total number of GFP+ of the cells placed in the wells on day 17. Mean and SD for each condition are shown 
a

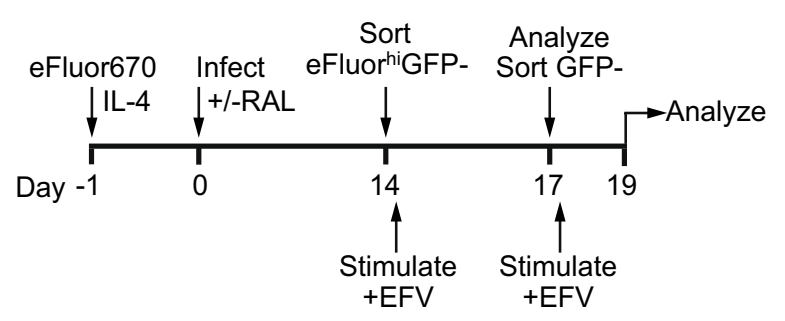

c

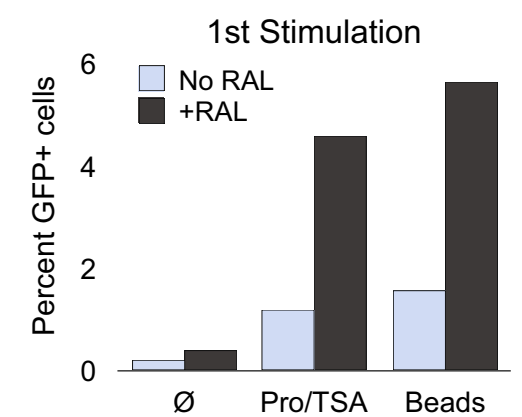

b

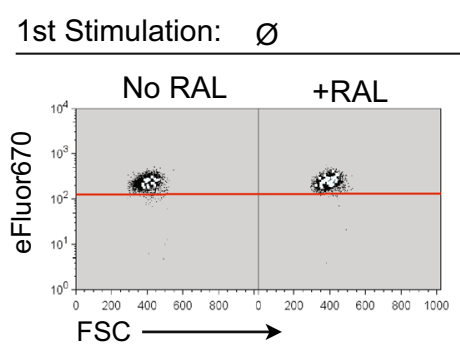

Pro/TSA

aCD3/CD28 beads
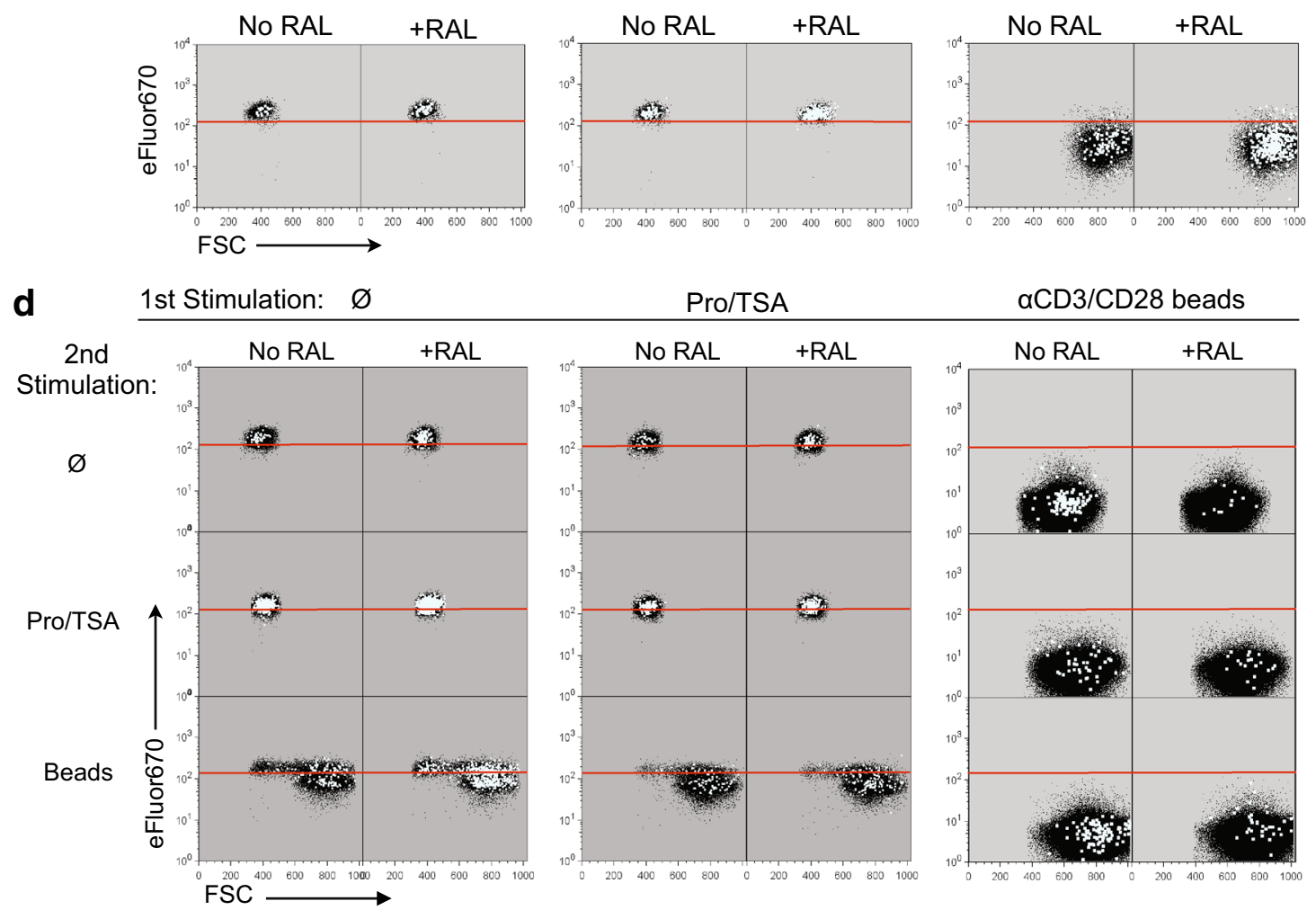

e

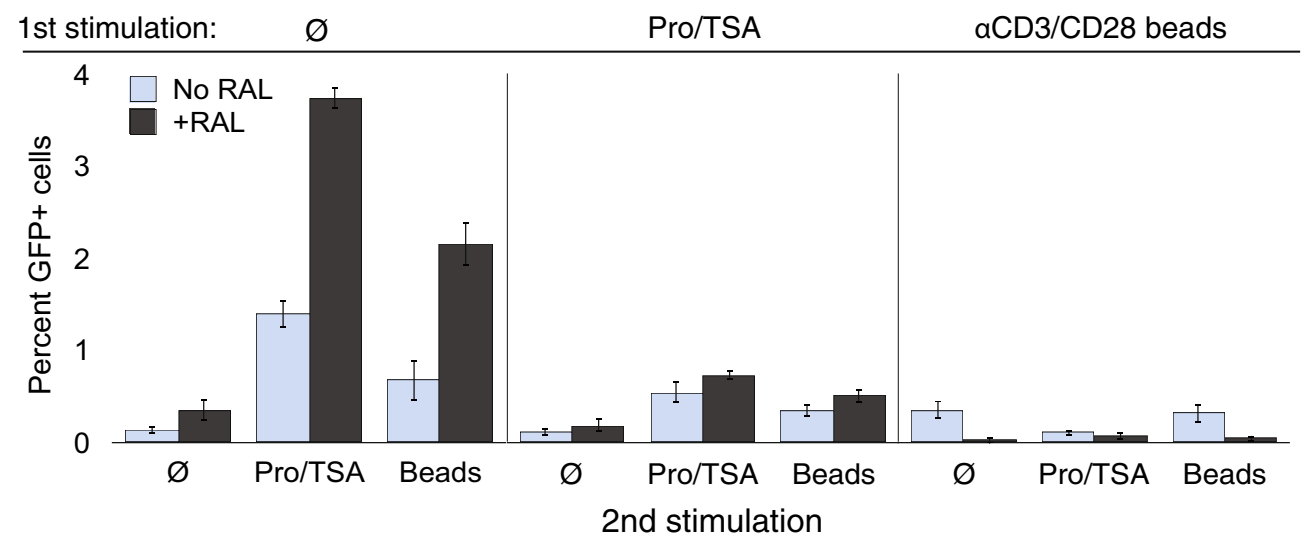




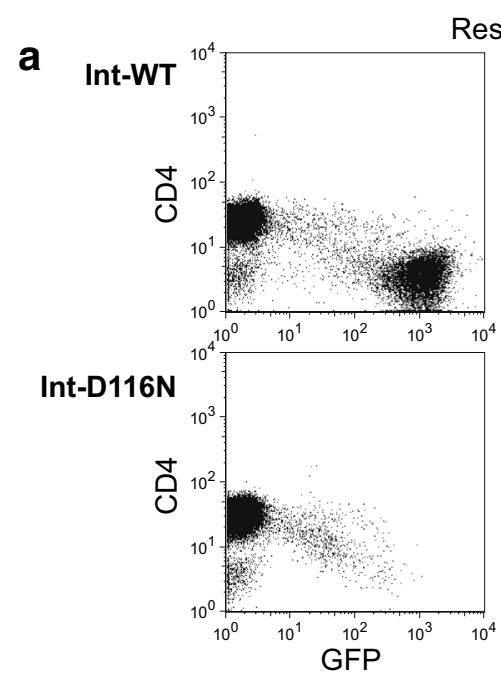

Resting
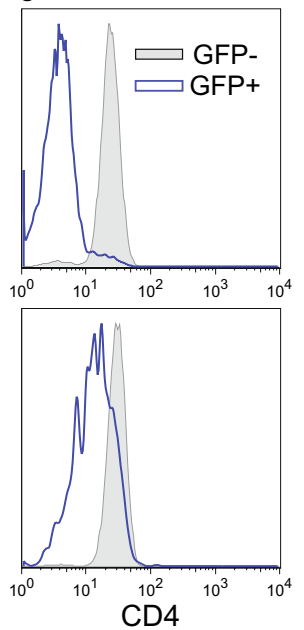

b
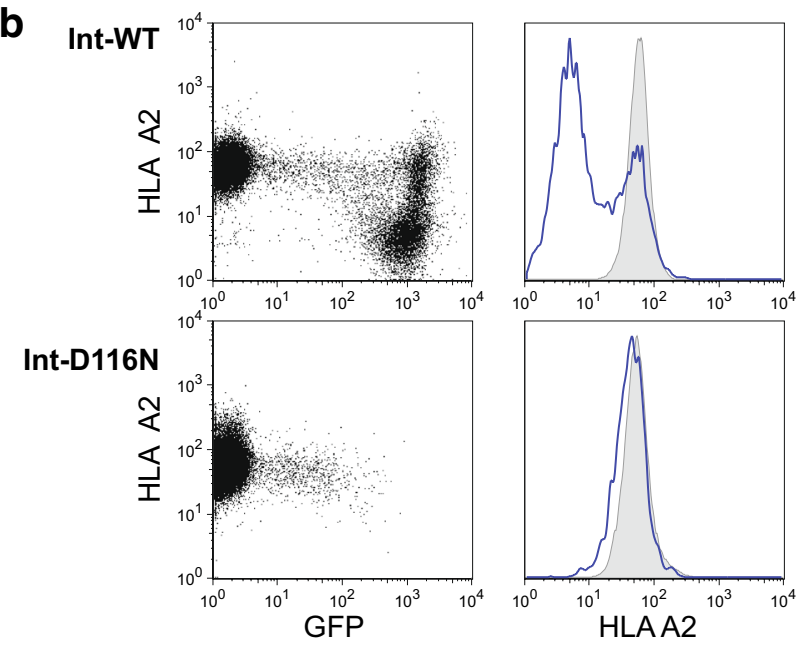

C

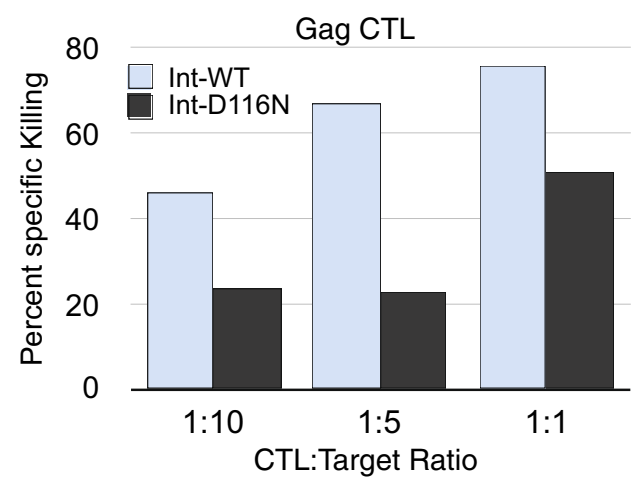

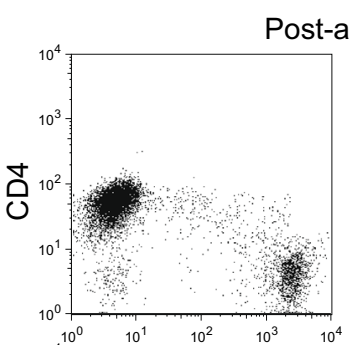
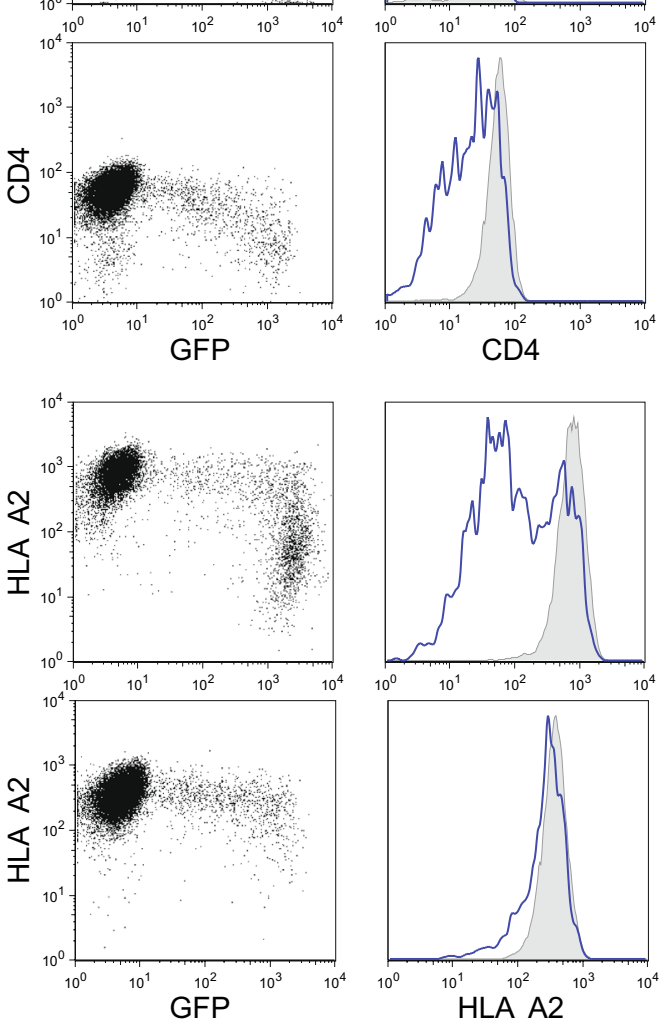

Nef CTL

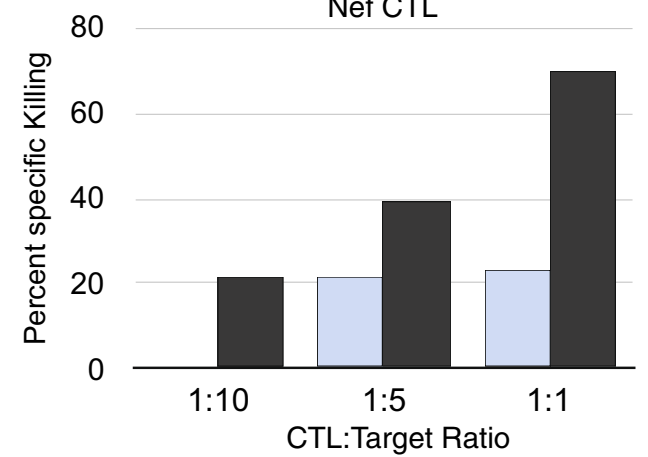

Fig. 7 Gene expression from uDNA fails to down modulate HLA Class I but is efficiently recognized by HIV-1-specific CTL. a Unintegrated HIV-1 down modulates CD4 in both resting (left) and activated (right) CD4 T cells. Resting IL-4 treated CD4 T cells were infected then analyzed 6 days after infection with Integrase wild type (Int-WT) or Integrase mutant (Int-D116N) HIV-1 GFP reporter viruses (left). One half of the cells were then activated with aCD3/CD28 beads then analyzed 2 days later (right). Activation caused a loss of a portion of GFP+ cells, resulting in fewer GFP+ at the time of analysis. The positive control CD4 down modulation data for the integrase WT virus was also a positive control in [43]. b Only integration-competent HIV-1 down modulates HLA A2 in resting (left) and post-infection activated (right) CD4 T cells. Cells were treated as in A but stained with an anti-HLA A2 antibody. c CD8+ cytotoxic T cells that recognize defined Gag and Nef epitopes (see materials and methods) specifically kill GFP+ cells infected with Int-WT or Int-D1 16N HIV-1. Killing was measured by loss of GFP+ cells, with non-specific killing of HLA Class I mismatched controls subtracted from the total. One of two representative experiments is shown 


\section{Discussion}

The findings presented here and in our prior studies $[6$, 14,68 ] challenge the notion that uDNA is inevitably a replicative dead end. Instead, latency, gene expression and virus production from unintegrated HIV-1 DNA are natural and possibly unavoidable consequences of the direct infection of resting CD4 T cells. In this in vitro setting, we found evidence that gene expression from uDNA is regulated somewhat differently from iDNA during productive infection, as only uDNA required an interval of several days after infection to obtain responsiveness to activating agents. Furthermore, latent uDNA demonstrated a wider dynamic range of responses to latency reversing agents and slower activation kinetics compared to latent integrated proviruses. Our prior work demonstrated that uDNA but not iDNA depends on virionassociated $\mathrm{Vpr}$ for expression in resting $\mathrm{T}$ cells further demonstrates qualitative differences in gene regulation between these forms of HIV-1 genomes [6].

HIV-1 uDNA surprisingly had a persistence advantage over integrated proviruses in resting CD4 $\mathrm{T}$ cells, which we attribute to reduced cytotoxicity resulting from uDNA's lower gene expression. As a result, resting CD4 $T$ cells expressed proteins and viruses from unintegrated genomes for longer than from integrated proviruses. The extended persistent expression from uDNA vs. iDNA was evident both during initial infection of cells and after reversal of latency. We also found that uDNA failed to down modulate HLA Class I surface expression on resting CD4 T cells, and HIV-1-specific CTL efficiently killed cells infected with unintegrated HIV-1. Thus, in vivo, uDNA may contribute to the development of anti-HIV-1 immune responses and to immune-dependent cell loss.

The de novo synthesis of virions from unintegrated HIV-1 requires a particular set of conditions that is clearly not the majority circumstance in vivo, and virus production by unintegrated HIV-1 in resting CD4 T cells is usually about one order of magnitude lower than from viruses which were capable of integration. Importantly, in vivo, most viruses are generated from activated $\mathrm{T}$ cells, which generate several-fold more viruses than resting T cells [69], and which we confirmed in [6] do not support high level gene expression and de novo virus production from uDNA. Thus, the finding that uDNA is capable of latency and virus production do not challenge the accepted view that HIV-1 predominantly replicates via the successfully integrated provirus. These findings are also consistent with the documented efficacy of raltegravir in vivo. We have identified an exception to the rule regarding the necessity of integration for de novo virus production and persistence. Intriguingly a recent study observed persistence of an integrase-defective HIV-1 in a patient [70], and infectious virus production from uDNA has recently been reported in $\mathrm{T}$ cell lines [71].
Investigations into the regulation of HIV-1 latency rely heavily on in vitro models, with several prominent systems utilizing direct infection of resting $\mathrm{T}$ cells (reviewed in [30]). In light of the results presented here, the contribution of uDNA to systems employing direct infection of resting and/or non-proliferating cells warrants investigation, as these systems may generate some of their output (RNA, virions, GFP+ cells) from unintegrated HIV-1 DNA, especially when stimulation is provided at least 5 days after infection. In addition, the procedure we established to reveal HIV-1 replication from uDNA [6] parallels the protocols developed to characterize in vivo latency: culture resting CD4 T cells from HIV+ individuals ex vivo for about 6 days, then activate them $[56,72,73]$. This culture period was performed so that pre-integration complexes in recently infected cells, which have a half-life of 1 day [40], would disintegrate and the cDNA would not integrate in response to $\mathrm{T}$ cell activation. Our studies suggest that these procedures would in fact optimize gene expression from any remaining unintegrated HIV-1. On the other hand, when infected cells proliferate, uDNA gene expression does not lead to de novo virus production [6], so systems in which activated and dividing $\mathrm{T}$ cells are infected are unlikely to generate such high levels of uDNA gene expression [74, 75]. The use of a proliferation tracking dye (eFluor670) allowed us to isolate only the non-proliferated cells for study of the in vitro generated latent reservoir, where we found the vast majority of latent infection. This technique is potentially useful in other models of HIV latency where the cells have been stimulated or activated prior to infection.

The potential of shock and kill therapies to eliminate latent reservoirs will depend upon these cells dying after virus activation, either via viral cytopathic effects or by immune killing [76], which has been cast into some doubt [77]. Our data here indicate that gene expression from uDNA displays slower kinetics and is more benign to host cells than from integrated proviruses, so viral cytopathicity is a particularly unreliable mechanism for eliminating cells expressing HIV-1 from uDNA. The lack of uDNA cytopathicity in resting CD4 T cells counterintuitively translated into the aforementioned persistence of unintegrated vs. integrated genomes in our system. The generation of uDNA may bias against the kill portion of investigations performing direct infection of resting $\mathrm{T}$ cells.

Success of shock and kill will also depend upon activating all latent replication competent genomes; however, this task is complicated by the multifactorial nature of HIV-1 latency [78]. Among these factors, the availability and activity of transcription factors in cells of varying lineages and activation states, the installation of epigenetic 
controls, and virus integration into chromosomal regions that favor or disfavor gene expression can all complicate the development of universally effective LRA [79, 80]. Additionally, cellular activation does not necessarily induce all latent genomes [60,81], and subpopulations of latently infected cells may display varying "degrees of latency" [82] or are regulated with a strong stochastic component $[81,83]$. This variability obtains even to clonal latent cell lines [38]. Here, we provide evidence for a further complication that can apply to, at least, in vitro models of latency: unintegrated HIV-1 genomes contribute to latency when resting $\mathrm{CD} 4 \mathrm{~T}$ cells are directly infected, and, as has observed for integrated proviruses, a subset of latent uDNA genomes resist activation by single or double stimulation and contain a strong stochastic component to their expression. Our finding that uDNA gene expression is regulated by somewhat different rules than integrated proviruses could also complicate in vitro testing of therapeutics to purge viral reservoirs.

Two basic and non-exclusive models for the establishment of HIV-1 latency have been proposed. Siliciano and Chun, after analyzing quiescent blood CD4 T cells, initially suggested that a rapid return to quiescence of recently infected activated cells can induce transcriptional silencing, as necessary transcription factors are withdrawn. This model has the logical benefits that (1) most in vivo latency in blood resides within previously activated memory CD4 T cells, and (2) it has been commonly accepted, based on studies of purified blood $\mathrm{T}$ cells, that quiescent (resting) CD4 $\mathrm{T}$ cells are poorly infectible, though infection and latency are possible even without stimulation [24]. However, the blood contains only $2 \%$ of the body's lymphocytes, with $98 \%$ resident in tissues. Lymphoid and mucosal tissues are the predominant sites of HIV-1 replication, depletion and latency [29, 84]. Microenvironmental factors in tissues enable resting CD4 $\mathrm{T}$ cells to be directly infected by HIV-1, and these cells are the dominant targets of early infection [29]. It has also been shown that infection of both resting cells from lymphoid tissues and activated $\mathrm{T}$ cells results in rapid establishment of latency [25]. Thus, a possible second mechanism contributing to HIV-1 latency has been gaining traction, in which direct infection of resting but permissive cells allows HIV-1 to rapidly enter latency immediately or soon after reverse transcription and integration [24]. Within this scenario, the present work demonstrates that latency and ultimately virus replication can be established in the absence of integration.

The responses of latent uDNA to the panel of latency reversing agents, measured as the induction of GFP+ cells and virions from sorted GFP-negative cells treated with raltegravir, obeyed the same basic pattern as when integration was allowed to proceed. However, the dynamic range of de novo virus production was substantially greater from unintegrated HIV-1, with weak stimuli inducing roughly equal numbers of GFP + cells and $7-20 \%$ as many virions as when integration is not blocked, while strong stimuli induced 2-3 times as many GFP + cells and 30-66 \% as many virions within $24 \mathrm{~h}$ and up to $>200 \%$ more virions over 3 days. Thus, as the strength of the stimulus increased, relatively more uDNA genomes were recruited out of latency compared with integrated proviruses. This greater dynamic range of uDNA responses to LRA suggests that uDNA transcription is regulated differently from iDNA. Chromatin structures that are proximal to the HIV-1 transcriptional regulatory regions, chief among these being promoterproximal nucleosomes, regulate the susceptibility of HIV-1 to transcriptional activation. The ability of histone deacetylase inhibitors to reverse latency is thought to be due at least in part to the displacement of promoterproximal nucleosomes following histone acetylation. The responsiveness of uDNA from HIV-1 and other retroviruses to $\mathrm{HDACi}$, which has been observed before by others and by us $[6,44-46]$, is an indication that uDNA is also regulated by chromatin [44]. HDACi also activate many cellular genes, so the influences of HDACi on HIV-1 expression are likely complex and include multiple indirect effects. Nevertheless, our conclusion that uDNA is transcriptionally regulated by a set of criteria somewhat different from iDNA is supported by the notion that uDNA would lack chromosomal positional effects that an integrated gene would be subjected to, such as integration sites which favor or disfavor transcription, and integration near transcriptional regulatory sequences of cellular genes. In addition, Vpr's ability to transactivate uDNA [85], and our prior demonstration that $\mathrm{Vpr}$ is the critical determining factor in establishing uDNA but not iDNA transcriptional competence in resting CD4 T cells, emphasizes the differential transcriptional regulation of uDNA and iDNA [6]. Use of $\Delta v p r$ HIV-1 vectors to infect resting $\mathrm{CD} 4 \mathrm{~T}$ cells would fail to achieve expression from unintegrated viral DNA and could account for some of the variability among systems [86]. How Vpr may contribute to latency regulation is not clear, but some prior studies, including those from one of us, have indicated that Vpr can reactivate latent proviruses [87-90]. More recently, the cellular protein family TASK and the viral accessory protein $\mathrm{Vpu}$ has been shown to specifically down-modulate HIV-1 uDNA transcription in a NF- $\mathrm{kB}-$ depended manner [91].

Antiviral immunity, particularly cytotoxic $\mathrm{T}$ cells, is envisioned to assist eradication of cells containing recently activated viruses. However, CTL killing in this scenario cannot necessarily be taken for granted [77, 92], and CTL responses may not be efficient at sites of HIV-1 
replication in lymphoid tissues [93]. We observed that uDNA expression is unable to efficiently down modulate HLA Class I expression in resting or CD4 T cells that were subsequently activated, despite being able to down modulate CD4 expression [64]. HLA Class I is targeted by HIV-1 Nef, which has been shown previously to be expressed from uDNA, however, relatively higher levels of Nef are required to induce HLA Class I down modulation than CD4 down modulation. We predicted that failure to down modulate HLA Class I might leave cells expressing HIV-1 from uDNA particularly vulnerable to CTL killing. We observed that both Nef-specific and Gag-specific CTL killed autologous target cells infected either with integrase wild type HIV-1 or integrase defective virus. Interestingly, cells infected with integrase defective virus were killed more efficiently than WT virus by the Nef-specific CLT but less efficiently by the Gag CTL. It is tempting to speculate that this relates to the relative inefficiency of Gag expression by uDNA, especially in replicating cells [6]. Recent studies have shown that the viral reservoir is influenced by the susceptibility of cells to CTL killing [67, 94], and it will be important to examine how uDNA expression sensitizes various cell types at different activation states to these processes.

\section{Methods}

\section{Viruses}

Viruses have been described previously [6, 14, 37, 43]. With the exception of Fig. 5a which employed an Env+ virus, infectious virions were generated by co-transfection of 293T cells with a plasmid expressing the env gene-defective reporter virus and a plasmid expressing the CXCR4 trophic HIV-1 NL4-3 envelope, as described previously $[6,14,37]$. Virus stocks were filtered through a $0.45 \mu \mathrm{m}$ pore-sized filter and treated with benzonase $(50 \mu / \mathrm{ml}$, Novagen) to remove residual plasmid remaining from transfections, as described [14].

\section{Cells and infections}

Peripheral blood buffy coats from HIV-1-negative adults were purchased from the New York Blood Center. Isolation, culture, IL-4 treatment, eFluor670 staining and infection of resting $\mathrm{CD} 4 \mathrm{~T}$ cells have been described previously [6]. p24gag ELISA analysis on viral stocks indicated a range of $175-320 \mathrm{ng}$ p24gag $/ 10^{6}$ cells except as indicated in Additional file 1: Fig S3. The titers of the virus stocks were routinely determined by TaqMan RTqPCR for HIV-1 RNA and normalized as previously described [6]. Raltegravir (1 $\mu \mathrm{M}$ in water) was added immediately after infection and supplemented at day 3 and day 7 after infection. Maximally effective raltegravir dose in resting CD4 $\mathrm{T}$ cells was determined in [6] to be $0.3 \mu \mathrm{M}$. The HIV-protease inhibitor indinavir (IND) was used at $2 \mu \mathrm{M}$ in water and the NNRTi efavirenz (EFV) was used at $1 \mu \mathrm{g} / \mathrm{ml}$ in DMSO. All antiretrovirals were obtained from the NIH AIDS Research and Reference Reagent Program.

\section{Stimulation of cells with latency reversing agents}

The following conditions were utilized: $\alpha \mathrm{CD} 3 / \mathrm{CD} 28 \mathrm{~T}$ cell activation beads $(1 \mu \mathrm{l} / 40,000$ cells; Life Technologies), PHA-L (3 $\mu \mathrm{g} / \mathrm{ml}$ in PBS; Sigma), TNF- $\alpha$ (10 ng/ $\mathrm{ml}$ in PBS; Invitrogen), PMA (16.2 $\mu \mathrm{M}$ in DMSO; Fisher Scientific), prostratin (Pro; $330 \mathrm{nM}$ in DMSO; Santa Cruz Biotechnology), bryostatin-1 (30 nM in DMSO; Santa Cruz Biotechnology), trichostatin A (TSA; $130 \mathrm{nM}$ in DMSO; Fisher Scientific), JQ1 (1 $\mu \mathrm{M}$ in DMSO; kindly provided by James E. Bradner, Dana Farber Cancer Institute, Boston, MA), disulfiram (50 nM in DMSO; Tocris Bioscience), HMBA (1 $\mathrm{mM}$ in $\mathrm{dH}_{2} \mathrm{O}$; Sigma), valproic acid (5 mM in PBS, Sigma), SAHA (vorinostat; $335 \mathrm{nM}$ in DMSO; Santa Cruz Biotechnology), scriptaid (1.8 $\mu \mathrm{M}$ in DMSO; Santa Cruz Biotechnology), oxamflatin (500 nM in DMSO; Santa Cruz Biotechnology) and DMSO carrier control (0.1\% [14 mM], specific to Pro/TSA; Sigma). In the latency activation experiments, GFP-negative cells were plated at 30,000 cells per well in 96-well plates for stimulation. A supernatant sample from each treatment was collected $24 \mathrm{~h}$ later or at the indicated time point and cell GFP expression was concurrently analyzed by flow cytometry. Synergy index was calculated based on published methods [95]. Briefly: The percentage of GFP+ cells after stimulation by each drug was converted to fold induction by normalizing to the percentage of GFP+ cells in IL-4-only treatment. The fold induction of a combination treatment was then divided by the sum of the fold induction of each drug when used separately. A combination with an index of $>1$ was considered synergistic, while an index of 1 was considered to be additive and $<1$ was considered as inhibitory.

\section{Flow cytometry}

Flow cytometric analysis was performed on a FACSort flow cytometer (Becton-Dickinson) upgraded to 3 lasers and 5 color channels as previously described [6]. Cell proliferation was calculated using the Proliferation platform of the FlowJo software based on eFluor670 intensity. Anti-CD4 (RPA-T4), Anti-HLA Class I (HLA A2) PerCP-Cy 5.5 (BB7.2), Anti-HLA-DR PerCP-Cy 5.5 (G46-6) and Anti-HSA-PE (M1/69) antibodies were purchased from BD Biosciences. Anti-CD69 PerCP-Cy5.5 (FN50), and isotype control mouse IgG1к PerCP-Cy5.5 (MOPC-21) antibodies were purchased from BioLegend. Anti-CD25 PerCP-Cy 5.5 (BC96) antibody was from eBioscience. Cell sorting was performed using a BD FACSAria sorter at the NYU Langone Medical Centre Office 
of Collaborative Science Flow Cytometry Core Facility. Flow cytometry for the CTL killing assay was performed at the UAB Center for AIDS Research Flow Cytometry Core. Intracellular DNA and RNA were stained with 7-aminoactinomycin D (7-AAD) and pyronin Y (PY) as previously described [96].

\section{MACS separation of productively infected and non-productively infected cells}

After infection with murine HSA (CD24)-expressing reporter virus, primary $\mathrm{CD} 4 \mathrm{~T}$ cells were treated at 1 day p.i. with pronase (Fisher Scientific) to remove residual HSA molecules from the initial infection as in [14]. At the indicated time points, live cells were purified on a FicollPaque (GE Life Sciences) gradient, stained with a phycoerythrin (PE) labeled anti-mCD24 antibody (M1/69, BD Biosciences) and then bound to anti-PE magnetic microbeads (Miltenyi Biotec). HSA Positive and negative cells were separated using the MACS system (Miltenyi Biotec) according to manufacturer's protocol. Purity was routinely $>95 \%$. Cell survival was measured by forward and side scatter analysis.

\section{PCR methods for quantification of HIV-1 DNA and RNA}

All methods, including primers and TaqMan probes have been previously described $[6,43]$. Briefly, DNA from cells was purified using the DNeasy Blood \& Tissue kit or the AllPrep kit (Qiagen). Cell associated RNA and viral RNA in culture medium were prepared using the RNeasy kit (Qiagen). DNA was analyzed using the QuantiTect Probe PCR kit (Qiagen) and RNA was analyzed by RT-qPCR using the QuantiTect Probe RT-PCR kit (Qiagen). Integrated HIV-1 was detect by Alu PCR as described [6].

\section{CTL cell killing assay}

HLA I-restricted $\mathrm{CD}^{+}$Cytotoxic $\mathrm{T}$ cell lines reactive against HIV-1 peptides were developed from HIV-1+ individuals as described [97]. CTL clone 2B6 recognizes HLA B*5301 restricted Gagp24-QW9 (QASQEVKNW) epitope in Nef, while clone 2A3 recognizes HLA B*4002 restricted Nef-KL9 (KEKGGLEGL) epitope. Both these clones were obtained from a chronically HIV clade B infected patient expressing HLA-A*02(01, 09)/A*3201; $\mathrm{B}^{*} 4002 / \mathrm{B}^{*} 5301$ and $\mathrm{Cw}^{*} 0202 / \mathrm{Cw}^{*} 0401$. EBV transformed B lymphoblastoid cell-lines (BLCL) were developed from this patient's PBMC for use as targets in the killing assay. An HLA-I mismatched BLCL was used as a negative control (HLA-A*2904/A*3002; B*1503/B*5802;

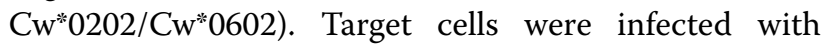
VSV-G pseudotyped NLENG1-ES-IRES or NLENG1-ESIRES-D116N as described [14, 37], resulting in 5-20\% GFP+ cells. Two days after infection, 50,000 infected target cells were co-cultured for $4 \mathrm{~h}$ with the CTL a three CTL:target ratios indicated in Fig. 7c. Cells were then harvested and stained with anti-CD19-PE-Cy7, anti-CD3-Pacific Blue, and anti-CD8-PerCP-Cy5.5 (BD Biosciences). Flow cytometry was performed on a $\mathrm{BD}$ FACSAria at the University of Alabama at Birmingham Center for AIDS Research Flow Cytometry Core Facility. Live cells were identified by side scatter and forward scatter profile, and live CD19+ CD3-CD8- cells were analyzed for percent GFP expression. Specific CTL killing of GFP + target cells was calculated in two steps: The GFP+ cells remaining after CTL exposure was calculated as a percentage of the number of CD19+ CD3-CD8-GFP+ cells present without CTL, then non-specific killing of HLA-mismatched target cells ( $<10 \%$ in all instances) was then subtracted from this number for each CTL:target ratio. This number was graphed as the Percent Specific Killing in Fig. 7c.

\section{Additional file}

Additional file 1: Figure S1 (supplement to Fig. 1). Integrase D116N mutant expression in resting CD4 T cells. An experiment performed independently from those in Figs. 1 and 2 was performed using a different donor. (A) Kinetics of virus expression with and without stimulation. (B) Loss of GFPhi population similar to raltegravir treatment of WT virus. Figure S2 (supplement to Fig. 1). Protein, RNA and DNA in GFP+ and GFP- cells at day 14 post infection. (A) HIV-GFP expression in cells at day 14 for analysis in E. Data are representative of $>5$ independent experiments using cells from different donors. MFI = mean fluorescence intensity of GFP. (B) Intracellular HIV-1 RNA in sorted cells from integration permissive (No RAL) and integration inhibited (+RAL) cultures. Early Rev-independent Fully spliced RNA, and late Rev-dependent unspliced RNA were quantified by RT-qPCR (see methods). Data are normalized to Fully spliced RNA in the GFP + No RAL cells set as 100\%. Data from one of two similar experiments is shown. Standard deviations are from PCR triplicates. Non-proliferated cells were sorted for this analysis (Fig S4A-B). (C) qPCR analysis of Total and Integrated HIV-1 DNA in cells from Fig. 1E-F. Infection in the presence of raltegravir resulted in less than 1 in $500 \mathrm{GFP}+$ cells containing an integrated provirus. Figure $\mathbf{S 3}$ (supplement to Fig. 1). Lack of influence of $\mathrm{MOI}$ on the timing of HIV-1 gene expression and on No RAL Vs. + RAL latency in resting CD4 T cells. (A) Cells were infected as in Figure 1 except that different doses of HIV-1 were applied. Figure 1 employs $300 n g$ p24gag per million cells. Note that the $Y$ axis scales are adjusted to allow comparison of relative kinetics at different MOI. (B) Relative amounts of latency for No RAL and +RAL infections remain constant with varying $\mathrm{MOI}$. GFP-negative cells from each infection were sorted at Day 14 p.i. by FACS and stimulated with Pro/TSA in triplicates or DMSO. Expression of GFP one day after stimulation is shown. Data representative of 3 independent experiments with 3 different donors. Figure S4 (supplement to Fig 1). Homeostatic proliferation of IL-4 treated cells and resting status of the non-productively infected cells. (A) eFluor670 and GFP expression on day 14 p.i. Sorting gates are indicated by red boxes. Data are representative of $>5$ independent experiments using cells from different donors. (B) Analysis of cell proliferation on the day of sorting. The FlowJo Proliferation Platform was used to calculate the percentage of cells that had divided at least once. (C) Expression of T cell activation markers CD69, HLA-DR and CD25 on the eFluorhiGFP-negative cells one day after sorting. Data are representative of three independent experiments. (D) 7AAD-Pyronin $Y$ staining of eFluorhiGFP-negative cells one day after sort. As a positive control for cell cycle progression, uninfected CD4 T cells were activated with aCD3/CD28 beads four days prior to analysis. The arrow with * indicates cells with increased DNA content but low RNA levels that are apparently 
preparing for homeostatic proliferation. Data are representative of two independent experiments. Figure S5 (supplement to Fig 2). Expanded panel of latency reversing agents in a donor different from Fig. 2. Grey and black vertical lines represent expression levels from the IL-4-only negative controls for No RAL and +RAL conditions in order to better visualize induction from latency. (A) Percent GFP+ cells as in Fig. 2 for the expanded panel. (B) Mean fluorescence intensity (MFI) of the GFP+ cells. Table S1 (supplement to Fig 4). Calculations of ratios of UDNA to iDNA in sorted No RAL cells. Calculations of the ratios of integrated to total DNA in sorted cell populations for Fig. 4A and C. Table S2 (Supplement to Fig 4). Percentage of cells with only uDNA from 4 additional experiments. Results from 4 additional independent experiments utilizing different donor cells for comparison with Fig. 4. Figure $\mathbf{S 6}$ (supplement to Fig 5). Activation of productively infected cells accelerates death only when integration is allowed. HSA+ cells were isolated 8 days after infection and stimulated or not with aCD3/CD28 activation beads. Viability was assessed at the indicated times by flow cytometry as in Fig. 5 E. Similar results were obtained using the GFP virus and sorted GFP+ cells (not shown). Figure $\mathbf{S 7}$ (supplement to Fig 6). Two rounds of stimulation by Pro/TSA did not reverse all HIV-1 latency. (A) Experimental design. Infected cells were treated with DMSO (B) or Pro/TSA (C) on day 8 p.i., then washed and re-treated with the same compounds on day 11 post infection. GFP-neg. cells were sorted on day 14 p.i. and treated with IL-4, Pro/TSA or aCD3/CD28 activation beads + IL-2 for 2 days before analysis. Indinavir was added at day 0 and 7 p.i. as an additional precaution against second round infection.

\section{Authors' contributions}

CNC, BT, SM, AA and DNL carried out the molecular studies. DNL, SS and AB performed the CTL recognition study. DW and PAG assisted with data analysis. CNC and DNL drafted the manuscript. All authors read and approved the final manuscript.

\section{Author details}

${ }^{1}$ Department of Basic Science, New York University College of Dentistry, New York, NY 10010, USA. ${ }^{2}$ Department of Ecology and Evolutionary Biology, University of California, Irvine, School of Biological, Sciences, Irvine, CA 92697, USA. ${ }^{3}$ Department of Medicine, University of Alabama at Birmingham, Birmingham, AL 35294, USA.

\section{Acknowledgements}

This study was funded by NIH/NIAID Al078783 and Al1 18453 to DNL, Al093998 to DNL and DW and Al084772 and Al1 12566 to PAG. The UAB Center for AIDS Research Flow Cytometry Core was funded by NIH Al027767. We thank Guomiao Shen and Catarina Hioe (NYU Langone Medical Center) for p24 ELISA.

\section{Competing interests}

The authors declare that they have no competing interests.

Received: 21 October 2015 Accepted: 21 December 2015

Published online: 05 January 2016

\section{References}

1. Shaw GM, Hahn BH, Arya SK, Groopman JE, Gallo RC, Wong-Staal F. Molecular characterization of human T-cell leukemia (lymphotropic) virus type III in the acquired immune deficiency syndrome. Science. 1984;226(4679):1165-71.

2. Pang S, Koyanagi Y, Miles S, Wiley C, Vinters HV, Chen IS. High levels of unintegrated HIV-1 DNA in brain tissue of AIDS dementia patients. Nature. 1990;343(6253):85-9. doi:10.1038/343085a0.

3. Cara A, Reitz MS Jr. New insight on the role of extrachromosomal retroviral DNA. Leukemia. 1997;11(9):1395-9.

4. Sloan RD, Wainberg MA. The role of unintegrated DNA in HIV infection. Retrovirology. 2011;8:52. doi:10.1186/1742-4690-8-52

5. Wu Y, Marsh JW. Selective transcription and modulation of resting T cell activity by preintegrated HIV DNA. Science. 2001;293(5534):1503-6. doi:10.1126/science.1061548.
6. Trinité B, Ohlson EC, Voznesensky I, Rana SP, Chan CN, Mahajan S, Alster J, Burke SA, Wodarz D, Levy DN. An HIV-1 replication pathway utilizing reverse transcription products that fail to integrate. J Virol. 2013;87(23):12701-20. doi:10.1128/JVI.01939-13.

7. Iyer SR, Yu D, Biancotto A, Margolis LB, Wu Y. Measurement of human immunodeficiency virus type 1 preintegration transcription by using Revdependent Rev-CEM cells reveals a sizable transcribing DNA population comparable to that from proviral templates. J Virol. 2009;83(17):8662-73. doi:10.1128/JVI.00874-09.

8. Butler SL, Johnson EP, Bushman FD. Human immunodeficiency virus cDNA metabolism: notable stability of two-long terminal repeat circles. J Virol. 2002;76(8):3739-47. doi:10.1128/JVI.76.8.3739-3747.2002.

9. Pierson TC, Kieffer TL, Ruff CT, Buck C, Gange SJ, Siliciano RF. Intrinsic stability of episomal circles formed during human immunodeficiency virus type 1 replication. J Virol. 2002;76(8):4138-44. doi:10.1128/ JVI.76.8.4138-4144.2002.

10. Gillim-Ross L, Cara A, Klotman ME. HIV-1 extrachromosomal 2-LTR circular DNA is long-lived in human macrophages. Viral Immunol. 2005;18(1):1906. doi:10.1089/vim.2005.18.190.

11. Pace MJ, Graf EH, O'Doherty U. HIV 2-long terminal repeat circular DNA is stable in primary CD4+ T Cells. Virology. 2013;441 (1):18-21. doi:10.1016/j. virol.2013.02.028.

12. Liu KC, Lin BS, Gao AD, Ma HY, Zhao M, Zhang R, Yan HH, Yi XF, Lin SJ, Que JW, Lan XP. Integrase-deficient lentivirus: opportunities and challenges for human gene therapy. Curr Gene Ther. 2014;14(5):352-64.

13. Saenz DT, Loewen N, Peretz M, Whitwam T, Barraza R, Howell KG, Holmes $J M$, Good M, Poeschla EM. Unintegrated lentivirus DNA persistence and accessibility to expression in nondividing cells: analysis with class I integrase mutants. JVirol. 2004;78(6):2906-20. doi:10.1128/ JVI.78.6.2906-2920.2004

14. Gelderblom HC, Vatakis DN, Burke SA, Lawrie SD, Bristol GC, Levy DN. Viral complementation allows HIV-1 replication without integration. Retrovirology. 2008:5:60. doi:10.1186/1742-4690-5-60.

15. Haase AT. Perils at mucosal front lines for HIV and SIV and their hosts. Nat Rev Immunol. 2005;5(10):783-92. doi:10.1038/nri1705.

16. Miller CJ, Li Q, Abel K, Kim EY, Ma ZM, Wietgrefe S, La Franco-Scheuch L, Compton L, Duan L, Shore MD, Zupancic M, Busch M, Carlis J, Wolinsky S, Haase AT. Propagation and dissemination of infection after vaginal transmission of simian immunodeficiency virus. J Virol. 2005;79(14):9217-27. doi:10.1128/JVI.79.14.9217-9227.2005.

17. Haase AT. Early events in sexual transmission of HIV and SIV and opportunities for interventions. Annu Rev Med. 2011;62:127-39. doi:10.1146/ annurev-med-080709-124959.

18. Eisele E, Siliciano RF. Redefining the viral reservoirs that prevent HIV-1 eradication. Immunity. 2012;37(3):377-88. doi:10.1016/j. immuni.2012.08.010 (Epub 2012/09/25).

19. Zhang Z, Schuler T, Zupancic M, Wietgrefe S, Staskus KA, Reimann KA, Reinhart TA, Rogan M, Cavert W, Miller CJ, Veazey RS, Notermans D, Little S, Danner SA, Richman DD, Havlir D, Wong J, Jordan HL, Schacker TW, Racz P, Tenner-Racz K, Letvin NL, Wolinsky S, Haase AT. Sexual transmission and propagation of SIV and HIV in resting and activated CD4+ T cells. Science. 1999;286(5443):1353-7.

20. Zhang ZQ, Wietgrefe SW, Li Q, Shore MD, Duan L, Reilly C, Lifson JD, Haase AT. Roles of substrate availability and infection of resting and activated CD4+ T cells in transmission and acute simian immunodeficiency virus infection. Proc Natl Acad Sci USA. 2004;101(15):5640-5. doi:10.1073/ pnas.0308425101.

21. Chun TW, Engel D, Berrey MM, Shea T, Corey L, Fauci AS. Early establishment of a pool of latently infected, resting CD4(+) $T$ cells during primary HIV-1 infection. Proc Natl Acad Sci USA. 1998:95(15):8869-73.

22. Hatziioannou T, Del Prete GQ, Keele BF, Estes JD, McNatt MW, Bitzegeio J, Raymond A, Rodriguez A, Schmidt F, Mac Trubey C, Smedley J, Piatak M, Jr., KewalRamani VN, Lifson JD, Bieniasz PD. HIV-1-induced AIDS in monkeys. Science. 2014;344(6190):1401-5. doi: 10.1126/science.1250761.

23. Whitney JB, Hill AL, Sanisetty S, Penaloza-MacMaster P, Liu J, Shetty M, Parenteau L, Cabral C, Shields J, Blackmore S, Smith JY, Brinkman AL, Peter LE, Mathew SI, Smith KM, Borducchi EN, Rosenbloom DI, Lewis MG, Hattersley J, Li B, Hesselgesser J, Geleziunas R, Robb ML, Kim JH, Michael NL, Barouch DH. Rapid seeding of the viral reservoir prior to SIV viraemia in rhesus monkeys. Nature. 2014;512(7512):74-7. doi:10.1038/nature13594. 
24. Swiggard WJ, Baytop C, Yu JJ, Dai J, Li C, Schretzenmair R, Theodosopoulos T, O'Doherty U. Human immunodeficiency virus type 1 can establish latent infection in resting CD4+ T cells in the absence of activating stimuli. J Virol. 2005;79(22):14179-88. doi:10.1128/JVI.79.22.14179-14188.2005.

25. Chavez L, Calvanese V, Verdin E. HIV Latency Is Established Directly and Early in Both Resting and Activated Primary CD4 T Cells. PLoS Pathog. 2015;11(6):e1004955. doi:10.1371/journal.ppat.1004955

26. Bukrinsky MI, Stanwick TL, Dempsey MP, Stevenson M. Quiescent T lymphocytes as an inducible virus reservoir in HIV-1 infection. Science. 1991;254(5030):423-7

27. Zack JA, Arrigo SJ, Weitsman SR, Go AS, Haislip A, Chen IS. HIV-1 entry into quiescent primary lymphocytes: molecular analysis reveals a labile, latent viral structure. Cell. 1990;61(2):213-22.

28. Eckstein DA, Penn ML, Korin YD, Scripture-Adams DD, Zack JA, Kreisberg JF, Roederer M, Sherman MP, Chin PS, Goldsmith MA. HIV-1 actively replicates in naive CD4(+) T cells residing within human lymphoid tissues. Immunity. 2001;15(4):671-82.

29. Kinter A, Moorthy A, Jackson R, Fauci AS. Productive HIV infection of resting $C D 4+T$ cells: role of lymphoid tissue microenvironment and effect of immunomodulating agents. AIDS Res Hum Retroviruses. 2003;19(10):847-56. doi:10.1089/088922203322493012.

30. Spina CA, Anderson J, Archin NM, Bosque A, Chan J, Famiglietti M, Greene WC, Kashuba A, Lewin SR, Margolis DM, Mau M, Ruelas D, Saleh S, Shirakawa K, Siliciano RF, Singhania A, Soto PC, Terry VH, Verdin E, Woelk C, Wooden S, Xing S, Planelles V. An in-depth comparison of latent HIV-1 reactivation in multiple cell model systems and resting CD4+ T cells from aviremic patients. PLoS Pathog. 2013;9(12):e1003834. doi:10.1371/journal. ppat.1003834

31. Vella A, Teague TK, Ihle J, Kappler J, Marrack P. Interleukin 4 (IL-4) or IL-7 prevents the death of resting T cells: stat 6 is probably not required for the effect of IL-4. J Exp Med. 1997;186(2):325-30.

32. Ducrey-Rundquist $O$, Guyader M, Trono D. Modalities of interleukin7-induced human immunodeficiency virus permissiveness in quiescent $T$ lymphocytes. J Virol. 2002;76(18):9103-11.

33. Moutsopoulos NM, Vazquez N, Greenwell-Wild T, Ecevit I, Horn J, Orenstein J, Wahl SM. Regulation of the tonsil cytokine milieu favors HIV susceptibility. J Leukoc Biol. 2006;80(5):1145-55. doi:10.1189/jlb.0306142.

34. Horikoshi H, Kinomoto M, Kurosu T, Komoto S, Shiraga M, Otake T, Mukai T, Ikuta K. Resting CD4(+) T cells with CD38(+)CD62L(+) produce interleukin-4 which contributes to enhanced replication of T-tropic human immunodeficiency virus type 1. Virology. 2002;293(1):94-102. doi:10.1006/viro.2001.1272.

35. Zhang M, Clausell A, Robinson T, Yin J, Chen E, Johnson L, Weiss G, Sabbaj S, Lowe RM, Wagner FH, Goepfert PA, Kutsch O, Cron RQ. Host factor transcriptional regulation contributes to preferential expression of HIV type 1 in IL-4-producing CD4 T cells. J Immunol. 2012;189(6):2746-57. doi:10.4049/jimmunol.1103129.

36. Trinité $B$, Chan CN, Lee CS, Levy DN. HIV-1 Vpr- and reverse transcriptioninduced apoptosis in resting peripheral blood CD4 T cells and protection by common gamma-chain cytokines. J Virol. 2015;90(2):904-16. doi: 10.1128/JVI.01770-15.

37. Levy DN, Aldrovandi GM, Kutsch O, Shaw GM. Dynamics of HIV-1 recombination in its natural target cells. Proc Natl Acad Sci USA. 2004;101(12):4204-9. doi:10.1073/pnas.0306764101.

38. Kutsch O, Benveniste EN, Shaw GM, Levy DN. Direct and quantitative single-cell analysis of human immunodeficiency virus type 1 reactivation from latency. J Virol. 2002;76(17):8776-86. doi:10.1128/ JVI.76.17.8776-8786.2002.

39. Engelman A, Craigie R. Identification of conserved amino acid residues critical for human immunodeficiency virus type 1 integrase function in vitro. J Virol. 1992;66(11):6361-9.

40. Pierson TC, Zhou Y, Kieffer TL, Ruff CT, Buck C, Siliciano RF. Molecular characterization of preintegration latency in human immunodeficiency virus type 1 infection. J Virol. 2002;76(17):8518-31. doi:10.1128/ JVI.76.17.8518-8513.2002.

41. Lassen KG, Hebbeler AM, Bhattacharyya D, Lobritz MA, Greene WC. A flexible model of HIV-1 latency permitting evaluation of many primary CD4 T-cell reservoirs. PLoS One. 2012;7(1):e30176. doi:10.1371/journal. pone.0030176.

42. Thierry S, Munir S, Thierry E, Subra F, Leh H, Zamborlini A, Saenz D, Levy DN, Lesbats P, Saib A, Parissi V, Poeschla E, Deprez E, Delelis O.
Integrase inhibitor reversal dynamics indicate unintegrated HIV-1 dna initiate de novo integration. Retrovirology. 2015;12(1):24. doi:10.1186/ s12977-015-0153-9.

43. Trinité B, Chan CN, Lee CS, Mahajan S, Luo Y, Muesing MA, Folkvord JM, Pham M, Connick E, Levy DN. Suppression of Foxol activity and downmodulation of CD62L (L-selectin) in HIV-1 infected resting CD4 T cells. PLoS One. 2014;9(10):e110719. doi:10.1371/journal.pone.0110719.

44. Kantor B, Ma H, Webster-Cyriaque J, Monahan PE, Kafri T. Epigenetic activation of unintegrated HIV-1 genomes by gut-associated short chain fatty acids and its implications for HIV infection. Proc Natl Acad Sci USA. 2009:106(44):18786-91. doi: 10.1073/pnas.0905859106

45. Schneider WM, Wu DT, Amin V, Aiyer S, Roth MJ. MuLV IN mutants responsive to HDAC inhibitors enhance transcription from unintegrated retroviral DNA. Virology. 2012;426(2):188-96. doi:10.1016/j.virol.2012.01.034.

46. Pelascini LP, Janssen JM, Goncalves MA. Histone deacetylase inhibition activates transgene expression from integration-defective lentiviral vectors in dividing and non-dividing cells. Hum Gene Ther. 2013;24(1):78-96. doi:10.1089/hum.2012.069.

47. Bosque A, Famiglietti M, Weyrich AS, Goulston C, Planelles V. Homeostatic proliferation fails to efficiently reactivate HIV-1 latently infected central memory CD4+ T cells. PLoS Pathog. 2011;7(10):e1002288. doi:10.1371/ journal.ppat.1002288.

48. Dar RD, Hosmane NN, Arkin MR, Siliciano RF, Weinberger LS. Screening for noise in gene expression identifies drug synergies. Science. 2014;344(6190):1392-6. doi:10.1126/science.1250220.

49. Bullen CK, Laird GM, Durand CM, Siliciano JD, Siliciano RF. New ex vivo approaches distinguish effective and ineffective single agents for reversing HIV-1 latency in vivo. Nat Med. 2014;20(4):425-9. doi:10.1038/nm.3489.

50. Spivak AM, Andrade A, Eisele E, Hoh R, Bacchetti P, Bumpus NN, Emad F, Buckheit R 3rd, McCance-Katz EF, Lai J, Kennedy M, Chander G, Siliciano RF, Siliciano JD, Deeks SG. A pilot study assessing the safety and latencyreversing activity of disulfiram in HIV-1-infected adults on antiretroviral therapy. Clin Infect Dis. 2014;58(6):883-90. doi:10.1093/cid/cit813.

51. Bonczkowski P, De Spiegelaere W, Bosque A, White CH, Van Nuffel A, Malatinkova E, Kiselinova M, Trypsteen W, Witkowski W, Vermeire J, Verhasselt B, Martins L, Woelk CH, Planelles V, Vandekerckhove L. Replication competent virus as an important source of bias in HIV latency models utilizing single round viral constructs. Retrovirology. 2014;11:70. doi:10.1186/ s12977-014-0070-3.

52. Hazuda DJ, Felock P, Witmer M, Wolfe A, Stillmock K, Grobler JA, Espeseth A, Gabryelski L, SchleifW, Blau C, Miller MD. Inhibitors of strand transfer that prevent integration and inhibit HIV-1 replication in cells. Science. 2000;287(5453):646-50.

53. Butler SL, Hansen MS, Bushman FD. A quantitative assay for HIV DNA integration in vivo. Nat Med. 2001;7(5):631-4. doi:10.1038/87979.

54. Kim SY, Byrn R, Groopman J, Baltimore D. Temporal aspects of DNA and RNA synthesis during human immunodeficiency virus infection: evidence for differential gene expression. J Virol. 1989;63(9):3708-13.

55. Spina CA, Guatelli JC, Richman DD. Establishment of a stable, inducible form of human immunodeficiency virus type 1 DNA in quiescent CD4 lymphocytes in vitro. J Virol. 1995;69(5):2977-88.

56. Chun TW, Carruth L, Finzi D, Shen X, DiGiuseppe JA, Taylor H, Hermankova M, Chadwick K, Margolick J, Quinn TC, Kuo YH, Brookmeyer R, Zeiger MA, Barditch-Crovo P, Siliciano RF. Quantification of latent tissue reservoirs and total body viral load in HIV-1 infection. Nature. 1997;387(6629):183-8. doi:10.1038/387183a0.

57. Middleton T, Lim HB, Montgomery D, Rockway T, Tang H, Cheng X, Lu L, Mo H, Kohlbrenner WE, Molla A, Kati WM. Inhibition of human immunodeficiency virus type I integrase by naphthamidines and 2-aminobenzimidazoles. Antiviral Res. 2004;64(1):35-45. doi:10.1016/j. antiviral.2004.04.007.

58. Svarovskaia ES, Barr R, Zhang X, Pais GC, Marchand C, Pommier Y, Burke TR Jr, Pathak VK. Azido-containing diketo acid derivatives inhibit human immunodeficiency virus type 1 integrase in vivo and influence the frequency of deletions at two-long-terminal-repeat-circle junctions. J Virol. 2004;78(7):3210-22.

59. Blazkova J, Chun TW, Belay BW, Murray D, Justement JS, Funk EK, Nelson A, Hallahan CW, Moir S, Wender PA, Fauci AS. Effect of histone deacetylase inhibitors on HIV production in latently infected, resting CD4(+) T cells from infected individuals receiving effective antiretroviral therapy. J Infect Dis. 2012;206(5):765-9. doi:10.1093/infdis/jis412. 
60. Ho YC, Shan L, Hosmane NN, Wang J, Laskey SB, Rosenbloom DI, Lai J, Blankson JN, Siliciano JD, Siliciano RF. Replication-competent noninduced proviruses in the latent reservoir increase barrier to HIV-1 cure. Cell. 2013;155(3):540-51. doi:10.1016/j.cell.2013.09.020.

61. Stevenson M, Haggerty S, Lamonica CA, Meier CM, Welch SK, Wasiak AJ. Integration is not necessary for expression of human immunodeficiency virus type 1 protein products. J Virol. 1990;64(5):2421-5.

62. Landi A, lannucci V, Nuffel AV, Meuwissen P, Verhasselt B. One protein to rule them all: modulation of cell surface receptors and molecules by HIV Nef. Curr HIV Res. 2011;9(7):496-504.

63. Cohen GB, Gandhi RT, Davis DM, Mandelboim O, Chen BK, Strominger J, Baltimore D. The selective downregulation of class I major histocompatibility complex proteins by HIV-1 protects HIV-infected cells from NK cells. Immunity. 1999;10(6):661-71.

64. Gillim-Ross L, Cara A, Klotman ME. Nef expressed from human immunodeficiency virus type 1 extrachromosomal DNA downregulates CD4 on primary CD4+ T lymphocytes: implications for integrase inhibitors. J Gen Virol. 2005;86(Pt 3):765-71. doi:10.1099/vir.0.80570-0.

65. Bansal A, Carlson J, Yan J, Akinsiku OT, Schaefer M, Sabbaj S, Bet A, Levy DN, Heath S, Tang J, Kaslow RA, Walker BD, Ndung'u T, Goulder PJ, Heckerman D, Hunter E, Goepfert PA. CD8 T cell response and evolutionary pressure to HIV-1 cryptic epitopes derived from antisense transcription. J Exp Med. 2010;207(1):51-9. doi:10.1084/jem.20092060.

66. Akinsiku OT, Bansal A, Sabbaj S, Heath SL, Goepfert PA. Interleukin-2 production by polyfunctional HIV-1-specific CD8 T cells is associated with enhanced viral suppression. J Acquir Immune Defic Syndr. 2011;58(2):132-40. doi:10.1097/QAl.0b013e318224d2e9.

67. Graf EH, Pace MJ, Peterson BA, Lynch LJ, Chukwulebe SB, Mexas AM, Shaheen F, Martin JN, Deeks SG, Connors M, Migueles SA, O'Doherty U. Gag-positive reservoir cells are susceptible to HIV-specific cytotoxic T lymphocyte mediated clearance in vitro and can be detected in vivo [corrected]. PLoS One. 2013;8(8):e71879. doi:10.1371/journal.pone.0071879.

68. Lau JW, Levy DN, Wodarz D. Contribution of HIV-1 genomes that do not integrate to the basic reproductive ratio of the virus. J Theor Biol. 2015;367:222-9. doi:10.1016/j.jtbi.2014.12.004.

69. Reilly C, Wietgrefe S, Sedgewick G, Haase A. Determination of simian immunodeficiency virus production by infected activated and resting cells. AIDS. 2007;21(2):163-8. doi:10.1097/QAD.0b013e328012565b.

70. Trabaud MA, Cotte L, Saison J, Ramiere C, Ronfort C, Venet F, Tardy JC, Monneret G, Andre P. Persistent production of an integrase-deleted HIV-1 variant with no resistance mutation and wild-type proviral DNA in a treated patient. AIDS Res Hum Retroviruses. 2015;31(1):142-9. doi:10.1089/AID.2014.0129.

71. Shimura K, Miyazato P, Oishi S, Fujii N, Matsuoka M. Impact of HIV-1 infection pathways on susceptibility to antiviral drugs and on virus spread. Virology. 2015;484:364-76. doi:10.1016/j.virol.2015.06.029.

72. Finzi D, Hermankova M, Pierson T, Carruth LM, Buck C, Chaisson RE, Quinn TC, Chadwick K, Margolick J, Brookmeyer R, Gallant J, Markowitz M, Ho DD, Richman DD, Siliciano RF. Identification of a reservoir for HIV-1 in patients on highly active antiretroviral therapy. Science. 1997;278(5341):1295-300

73. Wong JK, Hezareh M, Gunthard HF, Havlir DV, Ignacio CC, Spina CA, Richman DD. Recovery of replication-competent HIV despite prolonged suppression of plasma viremia. Science. 1997;278(5341):1291-5.

74. Bosque A, Planelles V. Induction of HIV-1 latency and reactivation in primary memory CD4+ T cells. Blood. 2009;113(1):58-65. doi:10.1182/ blood-2008-07-168393.

75. Xing S, Bullen CK, Shroff NS, Shan L, Yang HC, Manucci JL, Bhat S, Zhang $H$, Margolick JB, Quinn TC, Margolis DM, Siliciano JD, Siliciano RF. Disulfiram reactivates latent $\mathrm{HIV}-1$ in a $\mathrm{BCl}$-2-transduced primary $\mathrm{CD} 4+\mathrm{T}$ cell model without inducing global T cell activation. J Virol. 2011;85(12):60604. doi:10.1128/JVI.02033-10.

76. Deeks SG. HIV: Shock and kill. Nature. 2012;487(7408):439-40. doi:10.1038/487439a (Epub 2012/07/28).

77. Shan L, Deng K, Shroff NS, Durand CM, Rabi SA, Yang HC, Zhang H, Margolick JB, Blankson JN, Siliciano RF. Stimulation of HIV-1-specific cytolytic T lymphocytes facilitates elimination of latent viral reservoir after virus reactivation. Immunity. 2012;36(3):491-501. doi:10.1016/j. immuni.2012.01.014.

78. Lassen K, Han Y, Zhou Y, Siliciano J, Siliciano RF. The multifactorial nature of HIV-1 latency. Trends Mol Med. 2004;10(11):525-31. doi:10.1016/j. molmed.2004.09.006 (Epub 2004/11/03)
79. Winslow BJ, Pomerantz RJ, Bagasra O, Trono D. HIV-1 latency due to the site of proviral integration. Virology. 1993;196(2):849-54. doi:10.1006/ viro.1993.1545.

80. Shan L, Siliciano RF. From reactivation of latent HIV-1 to elimination of the latent reservoir: the presence of multiple barriers to viral eradication. BioEssays. 2013;35(6):544-52. doi:10.1002/bies.201200170.

81. Razooky BS, Pai A, Aull K, Rouzine IM, Weinberger LS. A hardwired HIV latency program. Cell. 2015;160(5):990-1001. doi:10.1016/j. cell.2015.02.009.

82. Donahue DA, Wainberg MA. Cellular and molecular mechanisms involved in the establishment of HIV-1 latency. Retrovirology. 2013;10:11. doi:10.1186/1742-4690-10-11.

83. Weinberger AD, Weinberger LS. Stochastic fate selection in HIV-infected patients. Cell. 2013;155(3):497-9. doi:10.1016/j.cell.2013.09.039.

84. Brenchley JM, Schacker TW, Ruff LE, Price DA, Taylor JH, Beilman GJ, Nguyen PL, Khoruts A, Larson M, Haase AT, Douek DC. CD4+ T cell depletion during all stages of HIV disease occurs predominantly in the gastrointestinal tract. J Exp Med. 2004;200(6):749-59. doi:10.1084/ jem.20040874.

85. Poon B, Chen IS. Human immunodeficiency virus type 1 (HIV-1) Vpr enhances expression from unintegrated HIV-1 DNA. J Virol. 2003;77(7):3962-72

86. Shen A, Baker JJ, Scott GL, Davis YP, Ho YY, Siliciano RF. Endothelial cell stimulation overcomes restriction and promotes productive and latent HIV-1 infection of resting CD4+ T cells. J Virol. 2013;87(17):9768-79. doi:10.1128/JVI.01478-13.

87. Levy DN, Refaeli Y, MacGregor RR, Weiner DB. Serum Vpr regulates productive infection and latency of human immunodeficiency virus type 1. Proc Natl Acad Sci USA. 1994;91(23):10873-7.

88. Levy DN, Refaeli Y, Weiner DB. Extracellular Vpr protein increases cellular permissiveness to human immunodeficiency virus replication and reactivates virus from latency. J Virol. 1995;69(2):1243-52.

89. Sherman MP, Schubert U, Williams SA, de Noronha CM, Kreisberg JF, Henklein P, Greene WC. HIV-1 Vpr displays natural protein-transducing properties: implications for viral pathogenesis. Virology. 2002;302(1):95-105.

90. Hoshino S, Konishi M, Mori M, Shimura M, Nishitani C, Kuroki Y, Koyanagi Y, Kano S, Itabe H, Ishizaka Y. HIV-1 Vpr induces TLR4/MyD88-mediated IL-6 production and reactivates viral production from latency. J Leukoc Biol. 2010;87(6):1133-43. doi:10.1189/jlb.0809547.

91. Emeagwali N, Hildreth JE. Human immunodeficiency virus type $1 \mathrm{Vpu}$ and cellular TASK proteins suppress transcription of unintegrated HIV-1 DNA. Virol J. 2012:9:277. doi:10.1186/1743-422X-9-277.

92. Deng K, Pertea M, Rongvaux A, Wang L, Durand CM, Ghiaur G, Lai J, McHugh HL, Hao H, Zhang H, Margolick JB, Gurer C, Murphy AJ, Valenzuela DM, Yancopoulos GD, Deeks SG, Strowig T, Kumar P, Siliciano JD, Salzberg SL, Flavell RA, Shan L, Siliciano RF. Broad CTL response is required to clear latent HIV-1 due to dominance of escape mutations. Nature. 2015;517(7534):381-5. doi:10.1038/nature14053.

93. Connick E, Mattila T, Folkvord JM, Schlichtemeier R, Meditz AL, Ray MG, McCarter MD, Mawhinney S, Hage A, White C, Skinner PJ. CTL fail to accumulate at sites of HIV-1 replication in lymphoid tissue. J Immunol. 2007;178(11):6975-83 (Epub 2007/05/22).

94. Buzon MJ, Yang Y, Ouyang Z, Sun H, Seiss K, Rogich J, Le Gall S, Pereyra F, Rosenberg ES, Yu XG, Lichterfeld M. Susceptibility to CD8 T-cellmediated killing influences the reservoir of latently HIV-1-infected CD4 T cells. J Acquir Immune Defic Syndr. 2014;65(1):1-9. doi:10.1097/ QAl.0b013e3182a1bc81.

95. Quivy V, Adam E, Collette Y, Demonte D, Chariot A, Vanhulle C, Berkhout B, Castellano R, de Launoit Y, Burny A, Piette J, Bours V, Van Lint C. Synergistic activation of human immunodeficiency virus type 1 promoter activity by NF-kappaB and inhibitors of deacetylases: potential perspectives for the development of therapeutic strategies. J Virol. 2002;76(21):11091-103. doi:10.1128/JVI.76.21.11091-11103.2002.

96. Schmid I, Cole SW, Korin YD, Zack JA, Giorgi JV. Detection of cell cycle subcompartments by flow cytometric estimation of DNA-RNA content in combination with dual-color immunofluorescence. Cytometry. 2000;39(2):108-16.

97. Sabbaj S, Bansal A, Ritter GD, Perkins C, Edwards BH, Gough E, Tang J, Szinger JJ, Korber B, Wilson CM, Kaslow RA, Mulligan MJ, Goepfert PA. Cross-reactive CD8+ T cell epitopes identified in US adolescent minorities. J Acquir Immune Defic Syndr. 2003;33(4):426-38. 